\title{
Why Are Health Care Report Cards So Bad (Good)?*
}

\author{
Yijuan Chen $^{\dagger}$ \\ Department of Economics, University of Pennsylvania
}

Job Market Paper 2008-12-22

\begin{abstract}
I provide a signaling-game theoretical foundation, upon which an updated empirical framework is proposed, to study the effects of issuing quality report cards for health care providers. I find that, when providers face an identical distribution of patient illness severity types, a trade-off between multidimensional measures in the existing report cards renders them a mechanism that reveals the providers' qualities without causing providers to select patients. However, non-identical patient type distributions between providers, attributed to the referring physician, may force the high-quality provider to shun patients in order to signal himself. Despite this imperfection, the existing report cards cause the minimum selection compared with alternative report mechanisms.

In contrast to prior research, my results imply that a single difference-in-differences estimate is not sufficient to indicate providers' selection behavior, and cannot capture the report cards' long run welfare effect with short run data. In my new empirical framework, a treatment effect will be estimated once every period.
\end{abstract}

Keywords: Report Cards, Signaling Game, Difference-in-differences, Experts JEL Classification: I18, D82, C31

${ }^{*}$ I am very grateful to Jan Eeckhout and Mark Pauly for their generous guidance and support. This paper also benefits from discussions with and comments from Elena Krasnokutskaya, Andrew Postlewaite, Petra Todd, David Dillenberger, George Mailath, Kenneth Wolpin, Roberto Pinheiro, Philipp Kircher, Rachel Werner, Daniel Polsky, Xun Tang, Guy David, and participants at Penn's Applied Micro Theory Workshop, Luncheon, and Wharton's Health Care Seminar.

$\dagger^{\dagger}$ E-mail: yijuan@sas.upenn.edu ; Webpage: www.sas.upenn.edu/ yijuan 


\section{Introduction}

In this paper I provide a theoretical foundation for empirically testing the effects of quality report cards in the health care industry, with particular focus on the well-known report cards for the coronary artery bypass graft (CABG) surgery. The report cards, planned to give outsiders better information about the quality of health care providers, have drawn doubts and criticisms since their inception. Arguably the most authoritative verdict comes from Dranove et al. (2003), who point out that, despite the risk adjustment procedures used in producing the report cards, "providers are likely to have better information on patients' conditions than even the most clinically detailed database" and may use such private information to improve their outcome by selecting patients. Using a single difference-in-differences estimate for each treatment effect, they show that report cards caused health care providers to avoid sicker patients and overall decreased social welfare. In other words, a solution toward adverse selection resulted in moral hazard.

The existing report cards, however, are worth deeper examinations for the following reasons. First, interpretations of empirical results in prior research are largely based on intuitions and/or conventional wisdom, lacking support of a solid theoretical foundation. Second, following prior research results, one may start searching for a new report mechanism, but if the existing report cards only need a small fix, then it will cost much less than a new mechanism, not to mention the new program may call for large and time-consuming institutional changes. Knowing how to fix the existing report cards, if the fixing is necessary at all, entails better understanding about the cards. In particular, a largely neglected fact is that the existing cards show multidimensional measures about the providers' performance ${ }^{1}$. How do these measures collectively affect the providers' decisions? How do the patients parse the report cards, and how do they interact with the providers? Moreover, how does a provider's decision vary with his true quality? A purely empirical approach cannot answer these questions in an integral way, and a theoretical signaling-game model is needed.

My studies toward the above positive questions lead to striking normative answers. First, even if the providers possess private patient information, when patients randomly choose providers, the existing report cards are actually the optimal mechanism in the sense that they fully reveal the providers' types without causing providers to select patients. The reason lies in the trade-off between two measures, volume and outcome, in the existing report cards. To improve outcome, measured by the mortality rate, a provider has to avoid sicker patients, resulting in a smaller patient volume. Due to this trade-off, when patients and providers are

\footnotetext{
${ }^{1}$ See Appendix 2 for a sample of the CABG report cards.
} 
matched randomly, a low-quality provider has no way to imitate a high-quality one. Consequently, no providers select patients and the report cards reveal true quality. ${ }^{2}$ This result on one hand provides a benchmark for studying the effects of the existing report cards, and on the other hand calls a stop to searching for a better mechanism under the assumption of identical patient distributions between providers.

I then investigate a more realistic situation where providers face non-identical distributions of patient types, attributed to the existence of the referring physician, with sicker patients matched to the high-quality provider. Sufficiently sick patients dampen the highquality provider's outcome, forcing him to shun sicker patients in order to signal his quality. The consequent selection behavior in a separating equilibrium is characterized by three ranges of the high-quality provider's type: In the bottom range, the degree of selection behavior increases with the provider's type, in the middle range, the degree decreases with his type, while in the top range, when the provider's quality is sufficiently high, there is no selection behavior. I further show that, despite their imperfection, the existing report cards cause the minimum selection behavior compared with alternative report mechanisms. This is because, given the existing cards have revealed all available information about a provider's performance, other report mechanisms necessarily temper the information from the existing report cards, only making it easier for the low-quality provider to imitate the high-quality one, and forcing the high-quality provider to shun more patients to separate himself.

The theoretical results shed new light on the empirical study. Based on the two-period signaling-game model, treatment effects of the report cards, including incidence effect, quantity effect, matching effect, and welfare effect, all vary across periods after the report-card program is enacted, thus requiring a difference-in-differences estimate for each treatment effect in each period. In contrast, the traditional single difference-in-differences estimate can only capture the average of the two periods' effects. Due to this, I propose an updated empirical framework to re-evaluate the effects of the report cards.

I show that, in contrast to prior research, a negative incidence effect, measured by a decrease of mean illness severity of surgical patients, can be caused either by providers selecting patients in period 1 or patients selecting providers in period 2, and therefore is not sufficient to indicate existence of providers' selection behavior. Specifically, when providers' types are revealed in the second period and so they accept all coming patients, in one scenario all sicker patients and a fraction of healthier patients will choose the high-quality provider, lowering his

\footnotetext{
${ }^{2}$ Though one may argue that, by shifting the distribution of illness severity toward healthy patients, the providers may improve outcome without cutting volume, the notion is self-contradictory, because it implies the providers will not be short of patient sources, and as a result they should not be concerned by the report cards, and there will be no selection behavior at the outset.
} 
mean of patient illness severity, and overall leading to a negative incidence effect. The reason, which counters the conventional wisdom that revelation of surgeon types results in only sicker patients being matched with the high-quality provider, is that a patient, healthier or sicker, is willing to seek the provider that gives her the best treatment. Hence healthier patients will continue choosing the high-quality provider until the large volume of patients drags down the high-quality provider's expected outcome.

Ultimately a report card should be evaluated by its welfare effect. Even though two periods suffice in the signaling game, in reality there may be more than one period after revelation of the providers' types. Hence the actual welfare effect is the sum of the (discounted) periodical effects. Since a single difference-in-differences estimate can only capture the average periodical effect, it cannot be used to estimate the long run welfare effect with short run data. More specifically, even though a negative period 1 effect may outweigh a positive period 2 effect, leading to a negative single difference-in-differences estimate based on short run data, the sum of all periods' effects may turn out to be positive, rendering the result from the single difference-in-differences estimate inconclusive. In contrast, since the estimation strategy based on my empirical framework estimates the periodical effects separately, one can use it to capture the long run welfare effect with short run data.

Despite inaccessibility of the data set used by Dranove et al. (2003) due to confidentiality of patient information, their estimation results offer circumstantial evidence for my theory due to one specification in their paper. Citing an augment of the New York report cards in 1993, Dranove et al. (2003) estimate each treatment effect under two assumptions: one with the New York report cards effective in 1991 and another with the effective year being 1993. Because the data since 1993 contain only period 2 New York data and period 1 Pennsylvania data while the data since 1991 in addition include period 1 New York data, a period 2 effect, if existing, should be more significant under the 1993 assumption. The regression results partially confirm this prediction. In particular, the post-surgery expenditure of sicker patients significantly increased only under the 1991 assumption, indicating the welfare effect is negative in period 1 but positive in period 2 .

More broadly, my results imply that the existing report cards, despite the criticism about their short run cost in the health care industry, have the potential to be successfully introduced to other industries where goods and services are provided by experts while customers and providers are matched randomly. Industries of interest include automobile service, law, and education.

The rest of the paper is organized as follows: I briefly review the background of the health care report cards and the previous literature in Section 2. The theoretical model is presented 
in Section 3, and the empirical framework and evidence are presented in Section 4. Section 5 concludes.

\section{Background and Previous Research}

Brief history: Starting in 1986 the U.S. Health Care Financing Administration (HCFA) produced the first wide-scale provider report cards. Since those report cards were based on hospital discharge abstracts, making a comprehensive risk adjustment scheme impossible, HCFA stopped releasing them in 1993. In December 1990, New York Department of Health publicly released the first statewide hospital-level CABG-specific report card, and in 1992 extended it to include the surgeon-level data. Other states followed. In December 1992, the Pennsylvania Health Care Cost Containment Council released its CABG report card at both hospital and surgeon level. New Jersey started collecting data in 1994 and released its first CABG report card in November 1997. Later states establishing CABG-related assessment programs include California, Washington, Massachusetts, and Michigan. For a detailed introduction to the history of the health care report cards in the U.S., see Epstein (2004).

Previous research: Since the inception of the CABG report cards, a large amount of literature, most of which based on survey or stand-alone empirical approaches, have been focused on studying their impact on the health care industry. For a comprehensive review, see Epstein (2006). Nonetheless, as Epstein (2006) points out, in the empirical literature "prior research...has failed to distinguish the effect of public reporting from other possible confounders associated with an underlying predisposition to performance improvement". One exception is Dranove et al.(2003), who in addition point out that "the failure of previous studies to consider the entire population at severity for CABG, rather than those who received it, is a potentially severe limitation". Using longitudinal cardiac-patient data from Medicare claims from 1987 to 1994, and hospital data from American Hospital Association, they estimate treatment effects of the report cards using a difference-in-differences approach. Based on the estimated negative incidence effects, they conclude that the report cards resulted in providers avoiding sicker patients. In addition, based on the estimated positive quantity effects, they suggest the report cards led the providers to shift distribution of patient illness severity toward healthier patients. Furthermore, they conclude that the report cards lead to decreased social welfare based on estimated increased post-surgical expenses and readmission rates. Using a similar approach with Florida as the control state, Epstein (2004) shows that mortality dropped in different patterns in New York, Pennsylvania and New Jersey around the time of the first report card publication. In addition Werner (2004) shows that racial and ethnic 
differences in CABG use rose significantly in New York after the state's CABG report card was released, which she attributes to physicians' belief about different clinic uncertainties in different racial and ethnic groups.

Despite the impact on surgery providers, literature that summarize survey information show that the report cards had small effect on the referring pattern of referring cardiologists. Based on a 1995 Pennsylvania survey, Schneider and Epstein (1996) show that $82 \%$ of surveyed cardiologists were aware of the report cards in 1995, but fewer than $10 \%$ discussed the guide with more than $10 \%$ of their patients needing CABG surgery. Hannan et al.(1997) show that, in New York, 85\% of surveyed cardiologists received the 1995 report card, but only $22 \%$ routinely discussed the report card with patients. Nonetheless the report cards did affect the difficulty at which the referring cardiologists place patients. Schneider and Epstein (1996) show that, 59\% of cardiologists reported increased difficulty since 1992 in placing their highseverity CABG patients, and $63 \%$ of cardiac surgeons reported being less willing to operate on those patients, offering circumstantial evidence for existence of selection behavior.

At the patient level, Omoigui et al. (1996) show that after the release of report cards in New York, the number of patients transferred to Ohio's Cleveland Clinic has increased by $31 \%$, and that in general the illness severity of these transferred patients was higher than those transferred to the Cleveland Clinic from other states, offering another circumstantial evidence for selection behavior caused by report cards. In addition Gibbs et al.(1996) show that most participants considered friends and relatives as highly credible and preferred these sources to published information, indicating that word-of-mouth is another channel of information diffusion.

Conclusions drawn from most of the empirical literature stemmed from intuitions and conventional wisdom, lacking support of a comprehensive and equilibrium-based theoretical framework. Among the exceptions is Epstein (2004), who studies a single surgeon's decision problem under the report-card program. Nonetheless the model lacks necessary components of a signaling-game model. In particular, it neglects the possibility that a low-quality surgeon may pool with the high-quality counterpart by imitating his performance. In addition, the model does not specify how patients interpret the reports card and base their belief about the surgeon type on it. In other words, the necessary belief system in a signaling game is absent. Fong (2007) proposes an alternative scoring rule in a setting with one provider, whose type, drawn from a binary variable, is unknown to the outsiders. The scoring rule is based on a one dimensional signal, namely the success rate. In equilibrium, however, the "good" type provider typically engages in selection behavior. Since she essentially assumes an identical distribution of patient types between both providers, the scoring rule she proposes is actually inferior 
to the existing report cards due to the trade-off between the measures in the existing ones. Another related paper is Lu et al. (2003). Using a Hotelling-class model, they study the effect of performance-based contracting on the providers. Though patient types are heterogeneous in their model, the types (locations) of providers are common knowledge, and so the model cannot be applied to study the effects of report cards.

\section{Theoretical Model}

\section{$3.1 \quad$ Set-up}

Time is discrete with 2 periods, indexed by $t \in\{1,2\}$.

Each period there are a continuum of patients with measure 1, who will be active for one period. A patient, indexed by $j$, has an illness severity type $s_{j}$ drawn from an identical and independent distribution with support $\mathbf{R}$ and a cumulative distribution function $F($.$) .$

There are 3 health care institutions, indexed by $i \in\{A, B, C\}$, of whom $A$ and $B$ are surgery providers and $C$ is a referring physician. A surgery provider $i$ is characterized by his quality type $k_{i} \in \mathbf{R}$. One provider's quality type is $k_{h}$, the other's being $k_{l}<k_{h}$. The providers' types are known to all the physicians but unknown to the patients, whereas the patients hold a prior belief that each provider is equally likely to be type $k_{l}$ or $k_{h} \cdot{ }^{3}$

Denote by $m_{i t}$ the measure of patients that provider $i$ performs the surgery on in period $t$. If $s_{j}=s, m_{i t}=m$, and $k_{i}=k$, the minimum probability of failure of the surgery on patient $j$ by provider $i$ is given by $q(s, m, k)$, which satisfies the following assumption:

\section{Assumption 1:}

(i) $\frac{\partial q}{\partial s} \geq 0$, with $\frac{\partial q}{\partial s}=0$ if and only if $q(s, m, k)=1$;

(ii) $\frac{\partial q}{\partial k} \leq 0$, with $\frac{\partial q}{\partial k}=0$ if and only if $q(s, m, k)=0$;

(iii) $\frac{\partial q}{\partial m} \geq 0$, with $\frac{\partial q}{\partial m}=0$ if and only if $q(s, m, k)=1 . \lim _{s \rightarrow-\infty} q(s, 1, k)=1, \lim _{s \rightarrow+\infty} q\left(s, 0, k_{h}\right)=$ 1 and $\lim _{s \rightarrow-\infty} q\left(s, 0, k_{l}\right) \in(0,1)$.

In Assumption 1, (i) and (ii) imply that the probability of failure is increasing with a patient's severity type and decreasing with the provider's quality. In (iii), $\frac{\partial q}{\partial m} \geq 0$ implies the capacity constraint faced by each provider, which comes from factors such as clinic facility,

\footnotetext{
${ }^{3}$ In contrast to simply assuming categorically a high type and a low type, my assumption allows continuity in the providers' types, in the sense that the difference between $k_{h}$ and $k_{l}$ now reflects how good a provider is relative to another. Intuitively, such a continuity captures the reality that although most of providers do differ in their quality, they may do so between "fair" and "very good", or "very good" and "excellent", instead of only between symbolically "good" and "bad".
} 
nursing, and logistic that affect a surgery's probability of failure ${ }^{4} \cdot \lim _{s \rightarrow-\infty} q(s, 1, k)=1$ reflects that, as a matter of reality, any provider, no matter how skillful, will be overwhelmed when $m=1$. The assumption $\lim _{s \rightarrow+\infty} q(s, 1, k)=1$ implies that when the severity type is sufficiently high, even the most skillful provider will fail for sure. $\lim _{s \rightarrow-\infty} q\left(s, 0, k_{l}\right) \in(0,1)$ reflects the minimum requirement for a provider to obtain a license and practice surgery. Moreover, the statement $q$ being the minimum probability of failure captures the fact that a provider is able to do worse, with the worst outcome being a certain failure. ${ }^{5}$

Each period a patient needs to visit $C$ before being referred to a provider $i$. A patient can decide which provider he would like to be referred to, and $C$ will make the referral according to the patient's choice. Alternatively the patient can leave the referral decision to $C$. If a patient $j$ is referred to provider $i$, his severity level is known by provider $i$ while remains unverifiable to himself. If it is up to $C$ to make the referral decision, $C$ 's decision will be characterized by the median severity level $s_{1 / 2}$ such that $F\left(s_{1 / 2}\right)=\frac{1}{2}$. C will refer patients with $s_{j}<s_{1 / 2}$ to the type $k_{l}$ provider and those with $s_{j} \geq s_{1 / 2}$ to the type $k_{h}$ provider.

My specification of $C$ 's referring pattern is worth some discussion. First, I assume that $C$ 's decision rule is not affected by report cards, which is consistent with the findings in the previous studies ${ }^{6}$ as discussed in Section 2. Second, the specification may seem stylized at the first glance, but it captures two important facts. On one hand, a referring physician, or more generally a primary care physician, is a generalist, whereas a surgery provider is a specialist. Hence the referring physician may only observe a category which a patient's severity level belongs to, while a surgery provider gains accurate information about the patient's type from his expertise and/or more advanced and more sophisticated examinations. On the other hand, referring physician is a characteristic feature of the now prevailing Managed Care Organizations $^{7}$. In this sense, a referring physician is a colleague of or has close relation with the surgery providers. C's referring pattern according to my specification thus ensures that each provider receives the same measure of patients while at the same time allows patients with higher severities to be matched with the provider with higher quality. I leave discussion about more general specifications of $C$ 's referring pattern, including the opposite case where $C$ refers healthier patients to the type $k_{h}$ provider and sicker patients to the type $k_{l}$ provider, to Subsection 3.3.

\footnotetext{
4 "An open-heart surgery team requires, among other things, skilled technicians, diagnostic imaging, and sophisticated laboratory support." Raffel \& Barsukiewicz, "The U.S. Health System, Origins and Functions", 5th Edition, page 126

${ }^{5}$ Chen $(2008 \mathrm{~b})$ shows that, as using "character evidence" is prohibited in the U.S. legal system, in the extreme case implicit collusion between providers will result in no litigation from the patient side.

${ }^{6}$ Schneider and Epstein (1996); Hannan et al. (1997)

${ }^{7}$ Phelps, C., "Health Economics", 3rd Edition, page 370, 375
} 
If patient $j$ is referred to provider $i$, the provider can choose between performing the surgery or providing an alternative treatment. A provider $i$ 's payoff is $\pi_{i}=m_{i 1}+m_{i 2}$, while the referring physician $C^{\prime}$ 's payoff is a constant ${ }^{8}$. I assume all the patients are Medicare beneficiaries and so monetary charges are abstracted from patients' payoffs ${ }^{9}$. The payoff of patient $j$ is 1 if the surgery succeeds and 0 if it fails. For simplicity I also assume a patient's payoff to be 0 if she undergoes the alternative treatment. Such an assumption allows a tractable analysis and also captures the worst possible scenario should the provider refuse performing surgery. While I discuss a more general assumption in Subsection 3.3, I would like to stress here that I believe my results are robust to the 0 payoff assumption.

At the end of period 1, a report card of provider $i$ will be published to the public, showing $\left(m_{i 1}, d_{i 1}\right)$, where $d_{i 1}$ is the mortality rate of the surgeries performed by $i$ in period 1 .

Denote by $\mathbf{P}$ a patient's mixed action set $\left\{\left(p_{A}, p_{B}, p_{C}\right) \mid \sum_{i} p_{i}=1\right.$ and $p_{i} \geq 0$ for $i \in$ $\{A, B, C\}\}$. An element of the action set, $\left(p_{A}, p_{B}, p_{C}\right)$, means that for $i \in\{A, B\}$ with probability $p_{i}$ the patient will ask $C$ to refer him to provider $i$ and with probability $p_{C}$ the patient will have $C$ make the referral decision. Denote a strategy of patient $j$ in period $t$ by $\phi_{j t}$, where $\phi_{j 1} \in \mathbf{P}$ and $\phi_{j 2}$ is a mapping from $j$ 's information set in period 2 to $\mathbf{P}$.

An action taken by provider $i$ in period $t$ is summarized by a set of patient types, denoted by $S_{i t}$. Only patients with $s_{j} \in S_{i t}$ will receive the surgery. Denote the set of $S_{i t}$ by $\mathbf{S}$. A strategy of provider $i$ is $\sigma_{i}=\left(\sigma_{i 1}, \sigma_{i 2}\right)$, where $\sigma_{i 1}:\left\{k_{l}, k_{h}\right\} \rightarrow \mathbf{S}$ and $\sigma_{i 2}:\left\{k_{l}, k_{h}\right\} \times[0,1]^{4} \rightarrow \mathbf{S}$.

Denote by $M_{i t}$ the measure of patients that are referred to $i$ in period $t$, and $F_{i t}$ the distribution of severity types in the patients referred to $i$ in $t$. When clear in the context, below I use $h$ in the subscript to denote the type $k_{h}$ provider and $l$ to denote the type $k_{l}$ provider.

\subsection{Analysis}

The solution concept is a symmetric perfect Bayesian equilibrium (PBE), consisting of a strategy profile $\left(\sigma_{A}^{*}, \sigma_{B}^{*}, \phi_{j t}^{*}\right)$ and a belief system, such that (i) given the other players' strategies specified in the profile each player's specified strategy is sequentially rational, (ii) the belief system is consistent with the strategy profile, and (iii) $\sigma_{A}^{*}=\sigma_{B}^{*}=\sigma^{*}, \phi_{j t}^{*}=\phi_{t}^{*}$ for every patient $j$.

I outline some preliminary results below before studying the equilibrium outcomes:

\footnotetext{
${ }^{8}$ Note that, whether $C$ is paid by a fixed salary or under a "fee for service" scheme, as long as the measure of patients seeking $C$ for referral is constant, $C$ 's payoff is a constant.

${ }^{9}$ Raffel M. W. \& Barsukiewicz C. K., "The U.S. Health System, Origins and Functions", 5th Edition, page $32-33$
} 
First, in period 2 it must be that each provider performs the surgery on all coming patients.

Second, two report cards are regarded as different if they differ in either one measure or both measures. An equilibrium is a separating one if in period 1 two providers generate different report cards. The concept of perfect Bayesian equilibrium then requires the patients in period 2 correctly infer the providers' types in a separating equilibrium. Consequently, in a separating equilibrium, if in period 2 the payoff of one type of provider is less than that of another, then in period 1 the former one must perform the surgery on all the coming patients. Throughout the analysis I will focus on separating equilibrium, and I discuss pooling equilibrium in the next subsection.

Third, under the prior belief, if patient $j$ chooses to make the referral decision on his own, he faces the probability distribution of matching between his severity type and a provider $i$ 's quality type as the table below

$$
\begin{array}{lll}
\text { Prob } & k_{i}=k_{h} & k_{i}=k_{l} \\
s_{i} \leq 1 / 2 & 1 / 4 & 1 / 4 \\
s_{i}>1 / 2 & 1 / 4 & 1 / 4
\end{array}
$$

while if he let $C$ make the referral decision, the matching probability table he faces is

$$
\begin{array}{lll}
\text { Prob } & k_{i}=k_{h} & k_{i}=k_{l} \\
s_{i} \leq 1 / 2 & 0 & 1 / 2 \\
s_{i}>1 / 2 & 1 / 2 & 0
\end{array}
$$

Denote by $E_{i t}$ both a patient $j$ 's expected payoff from being referred to provider $i$ at $t$ when he makes the decision on his own and his expected payoff from letting $C$ make the referral decision when $i=C$. There are, for $i \in\{A, B\}$,

$$
\left.E_{i 1}=\frac{1}{2} \int_{\sigma_{i 1}\left(k_{l}\right)} 1-q\left(s, m_{l 1}, k_{l}\right) d F(s)+\frac{1}{2} \int_{\sigma_{i 1}\left(k_{h}\right)} 1-q\left(s, m_{h 1}, k_{h}\right) d F(s)\right]
$$

and

$$
E_{C 1}=\int_{\sigma_{i 1}\left(k_{l}\right) \cap\left(-\infty, s_{1 / 2}\right)} 1-q\left(s, m_{l 1}, k_{l}\right) d F(s)+\int_{\sigma_{i 1}\left(k_{h}\right) \cap\left(s_{1 / 2},+\infty\right)} 1-q\left(s, m_{h 1}, k_{h}\right) d F(s)
$$

with $m_{l 1}=M_{i 1} \cdot \int_{\sigma_{i 1}\left(k_{l}\right)} d F_{i 1}(s)$, and $m_{h 1}=M_{i 1} \cdot \int_{\sigma_{i 1}\left(k_{h}\right)} d F_{i 1}(s)$.

Fourth, in any equilibrium it must be $E_{A 2}=E_{B 2}$ in period 2, since otherwise, say $E_{A 2}>$ $E_{B 2}$, all patients in period 2 will choose provider A, resulting in $M_{A 2}=1$ and so $E_{A 2}=0$ by Assumption 1, contradicting $E_{A 2}>E_{B 2}$. This result challenges the conventional wisdom that 
revelation of provider types will result in sicker patients choosing the high-quality provider and healthier patients choosing the low-quality one. A healthier patient after all is still a patient, whose objective is to seek the best possible treatment. Therefore the healthier patient also wants to choose the high-quality provider as long as he provides better outcome, and this will not cease until a large patient volume drags the high-quality provider's outcome to the same level as the low-quality one's.

Last, the period 2 patients' belief upon seeing identical report cards, i.e. $\left(m_{h 1}, d_{h 1}\right)=$ $\left(m_{l 1}, d_{l 1}\right)$, remains the same as the prior belief, since two identical cards cannot help the patients distinguish one provider from another.

Given these preliminary results, I first study a benchmark case where there is no referring physician $C$ and so the patients have to make decisions on their own, then I study the full model with $C$.

\subsubsection{Without $C$}

Without the referring physician $C$, in period 1 the patients will choose providers on their own and so $F_{i t}()=.F($.). With slight abuse of notation, I restrict the patients' actions to $\mathbf{P}$ such that $p_{C}=0$. Assumption 1 then implies that in equilibrium it must be $\phi_{1}^{*}=\left(\frac{1}{2}, \frac{1}{2}, 0\right)$. Intuitively, when patients have no other information about the providers' types, naturally they will randomize between the providers with equal probabilities. But when all the other patients randomize with equal probabilities, resulting in $M_{A 1}=M_{B 1}=\frac{1}{2}$, then a patient will be indifferent between the providers and so it is indeed his best response to also randomize with equal probabilities.

Lemma 1 below describes what will happen should the providers' types be revealed in period 2 .

Lemma 1 If the providers' types $\left(k_{i}, k_{-i}\right)$ are revealed in period 2, then there exists a unique

measure of patients $\hat{M}_{i 2}\left(k_{i}, k_{-i}\right)$ that will choose provider $i$ in period 2. Moreover, $\frac{\partial \hat{M}_{i 2}}{\partial k_{i}}>0$ and $\frac{\partial \hat{M}_{i 2}}{\partial k_{-i}}<0$.

Proof. In Appendix.

An immediate corollary of Lemma 1 is that, should the patients know the providers' types, then the provider with the higher quality type will receive more than $\frac{1}{2}$ measure of patients. For ease of notation, let $\hat{M}_{h}=\hat{M}_{i 2}\left(k_{h}, k_{l}\right)$ and $\hat{M}_{l}=1-\hat{M}_{h}$.

Denote by $\bar{d}_{i 1}$ the minimum mortality rate that provider $i$ can achieve. The lemma below characterizes $d_{i 1}$ as a function of the measure of $i^{\prime}$ s surgical patients. 
Lemma 2 For $m_{i 1} \in\left(0, M_{i 1}\right], \bar{d}_{i 1}\left(m_{i 1}\right)=\left[\int_{-\infty}^{F^{-1}\left(\frac{m_{i 1}}{M_{i 1}}\right)} q\left(s, m_{i 1}, k_{i}\right) d F(s)\right] \cdot \frac{m_{i 1}}{M_{i 1}}$, with $\frac{\partial \bar{d}_{i 1}}{\partial m_{i 1}}>0$

Proof. In Appendix.

Lemma 2 shows the trade-off facing a provider $i$ between the minimum mortality rate $\bar{d}_{i 1}$ and the measure of surgical patients $m_{i 1}$ : As shown in Figure 2-1, to improve (lower) the minimum mortality rate, the provider has to shun more sicker patients, which reduces the measure of patients he treats.

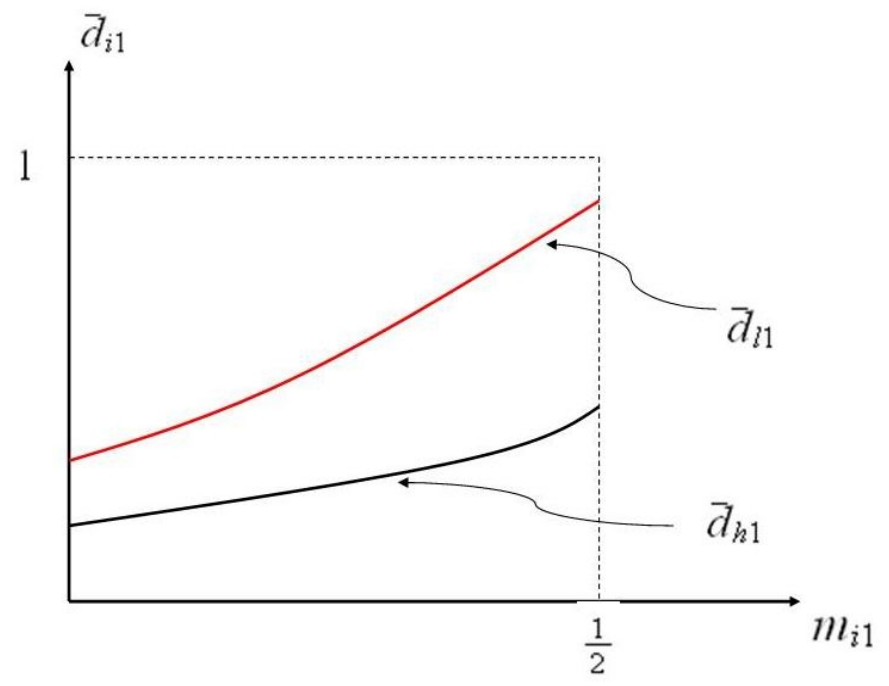

Firgure 2-1: Trade-off between $m_{i 1}$ and $\bar{d}_{i 1}$

Given $\left(M_{i 1}, k_{i}\right)$ we can define the set of provider $i$ 's possible report card results to be $\mathcal{Z}\left(M_{i 1}, k_{i}\right)=\left\{\left(m_{i 1}, d_{i 1}\right) \mid m_{i 1} \in\left(0, M_{i 1}\right], d_{i 1} \in\left[\bar{d}_{i 1}\left(m_{i 1}\right), 1\right]\right\}$ and we call the set $\mathbf{Z}\left(M_{i 1}, k_{i}\right)=$ $\left\{\left(m_{i 1}, \bar{d}_{i 1}\left(m_{i 1}\right)\right) \mid m_{i 1} \in\left(0, M_{i 1}\right]\right\}$ the frontier of $\mathcal{Z}\left(M_{i 1}, k_{i}\right)$.

At period 1, patients' equal randomization leads to $M_{i 1}=\frac{1}{2}$ for each provider, which implies

$$
\bar{d}_{i 1}=\int_{-\infty}^{+\infty} q\left(s, \frac{1}{2}, k_{i}\right) d F(s)
$$

and consequently $\bar{d}_{h 1}\left(\frac{1}{2}\right)<\bar{d}_{l 1}\left(\frac{1}{2}\right)$, as shown in Figure 2-1. Therefore, if the type $k_{h}$ provider performs the surgery on all the coming patients, then his report card will show $\left(\frac{1}{2}, \bar{d}_{h 1}\left(\frac{1}{2}\right)\right)$, which cannot be imitated by the type $k_{l}$ provider. Hence in a perfect Bayesian equilibrium, upon seeing $\left(\frac{1}{2}, \bar{d}_{h 1}\left(\frac{1}{2}\right)\right)$ the patients in period 2 must form a belief that the provider's type is certainly $k_{h}$. Therefore in period 1 performing surgeries on all the coming patients gives the type $k_{h}$ provider the highest possible payoff $\frac{1}{2}+\hat{M}_{h}$ and so dominates all the other actions. On the other hand, since the type $k_{l}$ provider by no means can imitate the type $k_{h}$ provider, it is 
the type $k_{l}$ provider's best response to perform surgeries on all the coming patients in period 1 too. The consistent belief system can be easily constructed accordingly. The proposition below summarizes these results:

Proposition 1 If there is no referring physician $C$, then there exists a unique separating equilibrium such that $\phi_{1}^{*}=\left(\frac{1}{2}, \frac{1}{2}, 0\right)$ and each provider performs the surgery on all coming patients. At period 2 the patients correctly infer the providers' types from the report cards and randomize between the providers in the way that they choose the type $k_{h}$ provider with probability $\hat{M}_{h}$ and the type $k_{l}$ provider with probability $\hat{M}_{l}$.

Proposition 1 implies that, when patients and providers are matched randomly, thanks to the trade-off between the volume measure, $m_{i 1}$, and the outcome measure $\bar{d}_{i 1}$, the existing report cards are actually the optimal mechanism that fully reveals the providers' types without causing selection behavior. This result shows the necessity of understanding the specific features of the existing report cards and their influence on the participants of the programs. Unfortunately, the feature of multidimensional measures in the existing report cards has been largely neglected in the previous studies, with some directly calling them "mortality report cards". Normative study such as Fong (2007) has also been conducted under the assumption that only mortality rates are released, while in the mean time implicitly assuming identical distribution of patient types between providers, and as a result the proposed mechanism is inferior to the existing report cards. Paying attention to the actual features of the existing report cards thus helps to avoid conducting research under unnecessarily unrealistic assumptions. Moreover, it is worth noting that, thanks to the absence of the referring physician $C$ here, the result in Proposition 1 is robust to the specification of $C$ 's objective and behavior. Therefore Proposition 1 provides a benchmark for further study on the report cards.

Proposition 1 also helps to clarify concerns from people that contemplate introducing the report-card program to other industries where goods and services are also provided by skilled experts. If in an industry the distributions of consumers among the providers are identical, then Proposition 1 shows the same report-card program can be successfully implemented there. If not, then one needs to exam the specific features of the industry to determine the report-card program's potential impact.

We now turn to the full model with the referring physician $C$.

\subsubsection{With $C$}

We first look at period 2. Suppose in period 2 the patients correctly infer the providers' types from the report cards, then in equilibrium the patients will not ask $C$ to make the 
referral decision, since otherwise each provider will receive patients with measure $1 / 2$, while $q\left(s, \frac{1}{2}, k_{h}\right)<q\left(s, \frac{1}{2}, k_{l}\right)$ implies a patient will strictly prefer choosing the type $k_{h}$ provider. However, on the other hand, a patient can induce more information about his severity type from turning to $C$ : If he asks $C$ to make the referral decision and is referred to, say, the type $k_{l}$ provider, then he will know that his severity type is below $s_{1 / 2}$. At this point the patient may want to reconsider the referral decision. To see how this extra information affects the patients' actions, I first show that when the patients know the providers' types, then with the extra information about severity types the period 2 patients' equilibrium actions derived in the previous section will no longer be part of an equilibrium even if

$$
1-\int_{-\infty}^{+\infty} q\left(s, \hat{M}_{h}, k_{h}\right) d F(s)>1-\left[\int_{-\infty}^{s_{1 / 2}} q\left(s, \hat{M}_{l}, k_{l}\right) d F(s)+\int_{s_{1 / 2}}^{+\infty} q\left(s, \hat{M}_{h}, k_{h}\right) d F(s)\right]
$$

where the left hand side is the payoff from seeing a type $k_{h}$ provider ${ }^{10}$, and the right hand side is the payoff from letting $C$ make the decision. The reason is that, the inequality implies

$$
1-\int_{-\infty}^{s_{1 / 2}} q\left(s, \hat{M}_{h}, k_{h}\right) d F(s)>1-\int_{-\infty}^{s_{1 / 2}} q\left(s, \hat{M}_{l}, k_{l}\right) d F(s)
$$

but now if a patient induces information from $C$ and knows that his severity type is below $s_{1 / 2}$, he will strictly prefer the type $k_{h}$ provider to the type $k_{l}$ provider, and so he would like to "renegotiate" with $C$ and choose the type $k_{h}$ provider for sure rather than randomizing between them or following $C$ 's decision. Therefore in this subsection I take into account this extra information when patients correctly infer the provider types from report cards, and allow a patient to base his action on both the providers' types and the category of his severity types characterized by $s_{1 / 2}$.

If a patient knows both the provider types and the category of his severity types, he can do at least as well as letting $C$ make the decision. Now there are three possibilities in a separating equilibrium regarding the distribution of patients' severity types facing the providers in period 2:

(i) All patients with $s_{j} \geq s_{1 / 2}$ and some with $s_{j}<s_{1 / 2}$ choose the type $k_{h}$ provider

(ii) All patients with $s_{j}<s_{1 / 2}$ and some with $s_{j} \geq s_{1 / 2}$ choose the type $k_{h}$ provider

(iii) Each provider is facing patients with all possible $s_{j}$ 's.

To analyze these possibilities, we see that, on one hand, for a patient with $s_{j} \geq s_{1 / 2}$ to be

\footnotetext{
${ }^{10}$ As discussed before it is equal to the payoff from seeing a type $k_{l}$ provider
} 
indifferent between a type $k_{h}$ provider and a type $k_{l}$ provider, it must be for some $\tilde{M}_{h} \in\left(\frac{1}{2}, 1\right]$

$$
Y\left(\tilde{M}_{h}\right) \equiv \int_{s_{1 / 2}}^{+\infty} q\left(s, \tilde{M}_{h}, k_{h}\right) d F(s)-\int_{s_{1 / 2}}^{+\infty} q\left(s, 1-\tilde{M}_{h}, k_{l}\right) d F(s)=0
$$

Since $Y\left(\frac{1}{2}\right)<0, Y(1)>0$, and $\frac{\partial Y}{\partial \tilde{M}_{h}}>0$, there exists a unique $\tilde{M}_{h}^{*}$ such that $Y\left(\tilde{M}_{h}^{*}\right)=0$. Note that $\tilde{M}_{h}^{*}$ is a function of $\left(k_{h}, k_{l}\right)$, and when necessary I will use the notation $\tilde{M}_{h}^{*}\left(k_{h}, k_{l}\right)$. Moreover, there is $\frac{\partial \tilde{M}_{h}^{*}}{\partial k_{h}}>0$. On the other hand, for a patient with $s_{j}<s_{1 / 2}$ to be indifferent between a type $k_{h}$ provider and a type $k_{l}$ provider, it must be for some $\bar{M}_{h} \in\left(\frac{1}{2}, 1\right]$

$$
G\left(\bar{M}_{h}\right) \equiv \int_{s_{1 / 2}}^{+\infty} q\left(s, \bar{M}_{h}, k_{h}\right)-q\left(s, 1-\bar{M}_{h}, k_{l}\right) d F(s)
$$

Similarly there exists a unique $\bar{M}_{h}^{*}$ such that $G\left(\bar{M}_{h}^{*}\right)=0$. Also $\bar{M}_{h}^{*}$ is a function of $\left(k_{h}, k_{l}\right)$ and when necessary I will use the notation $\bar{M}_{h}^{*}\left(k_{h}, k_{l}\right)$. Moreover, there is $\frac{\partial \bar{M}_{h}^{*}}{\partial k_{h}}>0$.

Now the aforementioned three possibilities correspond to the comparison between $\tilde{M}_{h}^{*}$ and $\bar{M}_{h}^{*}$ :

(i) $\tilde{M}_{h}^{*}>\bar{M}_{h}^{*}$, as shown in Figure 2

$$
\begin{aligned}
& s_{j} \geq s_{1 / 2} \underset{\frac{1}{2}}{\stackrel{h}{\frac{1}{2}} \quad h \prec l} \\
& h \succ l \quad h \prec l
\end{aligned}
$$

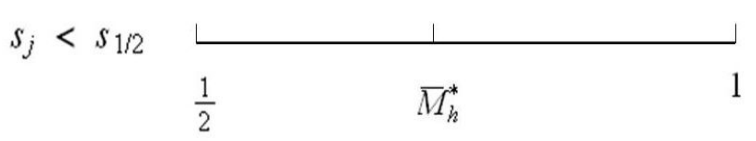

Figure 2-2: $\tilde{M}_{h}^{*}>\bar{M}_{h}^{*}$

Then in a separating equilibrium in period 2 it must be that all patients with severity types $s_{j} \geq s_{1 / 2}$ and a fraction $\frac{\bar{M}_{h}^{*}-\frac{1}{2}}{\frac{1}{2}}=2 \bar{M}_{h}^{*}-1$ of the patients with severity types $s_{j}<s_{1 / 2}$ choose the type $k_{h}$ provider, with the remaining patients choosing the type $k_{l}$ provider. In total in period 2 the type $k_{h}$ provider receives patients with measure $\bar{M}_{h}^{*}$ and the type $k_{l}$ provider receives $1-\bar{M}_{h}^{*}$ patients. The reason of such an outcome is, as $\tilde{M}_{h}^{*}>\bar{M}_{h}^{*}$, in the specified outcome the patients with severity types $s_{j} \geq s_{1 / 2}$ strictly prefer the type $k_{h}$ provider to the type $k_{l}$ provider $^{11}$, whereas the patients with severity types $s_{j}<s_{1 / 2}$ are indifferent between the two providers, and so no patients have the incentive to deviate. It is then easy, though

\footnotetext{
${ }^{11}$ On the other hand the patients with $s_{j} \geq s_{1 / 2}$ are indifferent between choosing the type $k_{h}$ surgeon on his own and letting $C$ make the referral decision.
} 
tedious, to verify that in any other outcomes at least one category of patients will have the incentive to deviate.

(ii) $\tilde{M}_{h}^{*}<\bar{M}_{h}^{*}$, as shown in Figure $2-3$

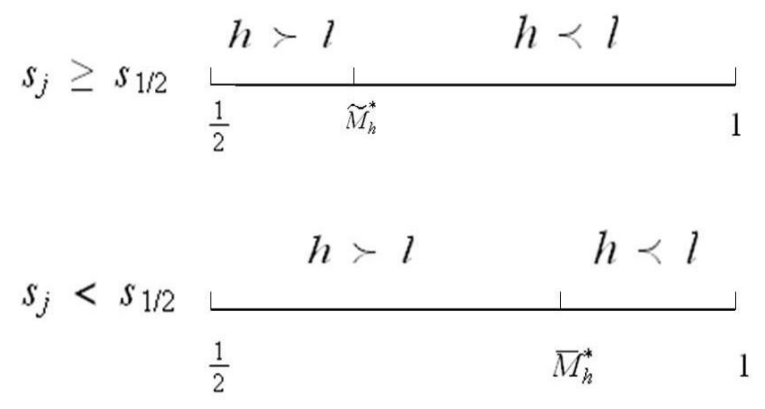

Figure 2-3: $\tilde{M}_{h}^{*}<\bar{M}_{h}^{*}$

Then in a separating equilibrium in period 2 all patients with severity types $s_{j}<s_{1 / 2}$ and a fraction $2 \tilde{M}_{h}^{*}-1$ of the patients with severity types $s_{j} \geq s_{1 / 2}$ choose the type $k_{h}$ provider, with the remaining patients choosing the type $k_{l}$ provider. In total in period 2 the type $k_{h}$ provider receives patients with measure $\tilde{M}_{h}^{*}$ and the type $k_{l}$ provider receives $1-\tilde{M}_{h}^{*}$ patients.

(iii) $\tilde{M}_{h}^{*}=\bar{M}_{h}^{*}$

Then in a separating equilibrium in period 2 the type $k_{h}$ provider receives $\tilde{M}_{h}^{*}$ patients. A fraction $\theta$ of patients with $s_{j} \geq s_{1 / 2}$ and a fraction $\gamma$ of patients with $s_{j}<s_{1 / 2}$ choose the type $k_{h}$ provider, with $\frac{1}{2} \theta+\frac{1}{2} \gamma=\tilde{M}_{h}^{*} \cdot{ }^{12}$

The fact that $\frac{\partial \tilde{M}_{h}^{*}}{\partial k_{h}}>0$ and $\frac{\partial \bar{M}_{h}^{*}}{\partial k_{h}}>0$ implies that the type $k_{h}$ provider's payoff increases with $k_{h}$ if the type is known by the patients. The lemma below summarizes the results obtained so far.

Lemma 3 If in period 2 the patients know both the providers' types and the category of their severity types characterized by $s_{1 / 2}$, then in equilibrium the type $k_{h}$ provider will receive patients with measure $M_{h}^{*}\left(k_{h}, k_{l}\right) \equiv \min \left\{\tilde{M}_{h}^{*}, \bar{M}_{h}^{*}\right\}$, and the type $k_{l}$ provider will receive patients with measure $1-M_{h}^{*}\left(k_{h}, k_{l}\right)$.

We now turn to period 1. There are two possible outcomes in the first period. The patients may make the referral decisions on their own, or leave the decision to the referring physician. The lemma below characterizes these possibilities.

\footnotetext{
${ }^{12}$ Note that $\tilde{M}_{h}^{*}=\bar{M}_{h}^{*}$ implies that $Y\left(\tilde{M}_{h}^{*}\right)+G\left(\tilde{M}_{h}^{*}\right)=\int_{-\infty}^{+\infty} q\left(s, \tilde{M}_{h}^{*}, k_{h}\right) d F(s)-\int_{-\infty}^{+\infty}\left(s, 1-\tilde{M}_{h}^{*}, k_{l}\right) d F(s)=$ $L\left(\tilde{M}_{h}^{*}\right)=0$, that is, $\tilde{M}_{h}^{*}=\bar{M}_{h}^{*}=\hat{M}_{h}$, but on the other hand $L\left(\hat{M}_{h}\right)=0$ does not necessarily mean $Y\left(\hat{M}_{h}\right)=0$ and $G\left(\hat{M}_{h}\right)=0$.
} 
Lemma 4 There exists a separating equilibrium such that in period 1 the patients make referral decisions on their own if and only if

$$
\int_{s_{1 / 2}}^{+\infty} q\left(s, \frac{1}{2}, k_{l}\right)-q\left(s, \frac{1}{2}, k_{h}\right) d F(s)<\int_{-\infty}^{s_{1 / 2}} q\left(s, \frac{1}{2}, k_{l}\right)-q\left(s, \frac{1}{2}, k_{h}\right) d F(s)
$$

Proof. In Appendix.

The intuition of Lemma 4 is: Compared with letting $C$ make the decision, there are benefit and cost of choosing a provider on one's own. The benefit comes from choosing a type $k_{h}$ provider when one's severity type is below $s_{1 / 2}$, while the cost comes from choosing a type $k_{l}$ provider when one's severity type is above $s_{1 / 2}$. For a patient to prefer self-referral to letting $C$ make the decision, it must be that the cost of self-referral, represented by the left hand side of the inequality in the lemma, is outweighed by the benefit, represented by the right hand side of the inequality.

The equilibrium outcome in the separating equilibrium with self referral in period 1 is similar as when there are no referring physician $C$. Equal randomization of the patients allows the type $k_{h}$ provider to separate himself from the type $k_{l}$ provider without shunning any patients, and consequently the type $k_{l}$ provider will not shun patients either. At period 2 , the report cards fully reveal the providers' types and the patients choose providers in the way implied by Lemma 2 and its preceding discussion.

When the inequality in Lemma 4 is reversed, the patients leave the referring decision to $C$. We now turn to this scenario.

If period 1 patients let $C$ make the referral decision, then $M_{i 1}=\frac{1}{2}$ for each provider $i$, but the providers face different distribution of severity types. Specifically, the type $k_{h}$ provider receives only patients with $s_{j} \geq s_{1 / 2}$, so $F_{h 1}(s)=\left\{\begin{array}{c}2 F(s)-1 \text { if } s_{j} \geq s_{1 / 2} \\ 0 \text { if } s_{j}<s_{1 / 2}\end{array}\right.$ whereas the type $k_{l}$ provider receives only patients with $s_{j}<s_{1 / 2}$, so $F_{l 1}(s)=\left\{\begin{array}{c}1 \text { if } s_{j} \geq s_{1 / 2} \\ 2 F(s) \text { if } s_{j}<s_{1 / 2}\end{array}\right.$.

Denote by $\bar{d}_{h 1}$ the minimum mortality rate that a type $k_{h}$ provider can achieve. The first part of the lemma below characterizes $d_{h 1}$ as a function of the measure of the type $k_{h}$ provider's surgical patients. The second part of the lemma provides a analogous characterization for $\bar{d}_{l 1}$, the minimum mortality rate that a type $k_{l}$ provider can achieve.

Lemma 5 (i) For $m_{h 1} \in\left(0, M_{h 1}\right], \bar{d}_{h 1}\left(m_{h 1}\right)=\int_{s_{1 / 2}}^{F_{h 1}^{-1}\left(\frac{m_{h 1}}{M_{h 1}}\right)} q\left(s, m_{h 1}, k_{h}\right) d F_{h 1}(s) \cdot \frac{m_{h 1}}{M_{h 1}}$, with $\frac{\partial \bar{d}_{h 1}}{\partial m_{h 1}}>0$ and $\frac{\partial \bar{d}_{h 1}}{\partial k_{h}}<0$. (ii) For $m_{l 1} \in\left(0, M_{l 1}\right], \bar{d}_{l 1}\left(m_{l 1}\right)=\int_{-\infty}^{F_{l 1}^{-1}\left(\frac{m_{l 1}}{M_{l 1}}\right)} q\left(s, m_{l 1}, k_{l}\right) d F_{l 1}(s) \cdot \frac{m_{l 1}}{M_{l 1}}$, with $\frac{\partial \bar{d}_{l 1}}{\partial m_{l 1}}>0$ and $\frac{\partial \bar{d}_{l 1}}{\partial k_{l}}<0$. 


\section{Proof. In Appendix}

Following Lemma 5, with $M_{i 1}=\frac{1}{2}$, for $m \in\left(0, \frac{1}{2}\right]$ we have

$$
\bar{d}_{h 1}(m)=\frac{1}{m} \cdot \int_{s_{1 / 2}}^{F^{-1}\left(m+\frac{1}{2}\right)} q\left(s, m, k_{h}\right) d F(s)
$$

and

$$
\bar{d}_{l 1}(m)=\frac{1}{m} \cdot \int_{-\infty}^{F^{-1}(m)} q\left(s, m, k_{l}\right) d F(s)
$$

Denote by $\bar{k}_{h}$ the type of $k_{h}$ that solves $\bar{d}_{h 1}\left(\frac{1}{2}\right)=\bar{d}_{l 1}\left(\frac{1}{2}\right)^{13}$. Also denote by $\underline{k}_{h}$ the type $k_{h}$ that solves $\lim _{m \rightarrow 0} \bar{d}_{h 1}(m)=\lim _{m \rightarrow 0} \bar{d}_{l 1}(m)^{14}$. The fact $\frac{\partial \bar{d}_{h 1}}{\partial k_{h}}<0$ implies that $k_{l}<\underline{k}_{h}<\bar{k}_{h}$.

$\underline{k}_{h}$ and $\bar{k}_{h}$ divide $k_{h}$ into three ranges. As shown in Table 2-1, for $k_{h}>\bar{k}_{h}$, the frontier of the type $k_{h}$ provider's report card results lies entirely outside the type $k_{l}$ provider's set of report card results, implying that if the type $k_{h}$ provider stays on the frontier, then the type $k_{l}$ provider cannot imitate his report card result. For $k_{h}<\bar{k}_{h}$, the set of the type $k_{h}$ provider's report card results becomes a proper subset of the type $k_{l}$ provider's set of report card results, meaning that the type $k_{l}$ can mimic any report card result from the type $k_{h}$ provider. For $k_{h} \in\left(\underline{k}_{h}, \bar{k}_{h}\right)$, There is a generic subset of the type $k_{h}$ provider's report card results that does not belong to the type $k_{l}$ provider's set of results, implying that the type $k_{l}$ provider can imitate the type $k_{h}$ provider, but only to a certain extent. The remaining non-generic cases are characterized by $k_{h}=\bar{k}_{h}$ and $k_{h}=\underline{k}_{h}$, as limits of the generic cases.

\begin{tabular}{|c|c|c|}
\hline & $\bar{d}_{h 1}\left(\frac{1}{2}\right)$ vs. $\bar{d}_{l 1}\left(\frac{1}{2}\right)$ & $\lim _{m \rightarrow 0} \bar{d}_{h 1}(m)$ vs. $\lim _{m \rightarrow 0} \bar{d}_{l 1}(m)$ \\
\hline$k_{h}>\bar{k}_{h}$ & $<$ & $<$ \\
\hline$k_{h}=\bar{k}_{h}$ & $=$ & $<$ \\
\hline$k_{h} \in\left(\underline{k}_{h}, \bar{k}_{h}\right)$ & $>$ & $<$ \\
\hline$k_{h}=\underline{k}_{h}$ & $>$ & $>$ \\
\hline$k_{h} \in\left(k_{l}, \underline{k}_{h}\right)$ & $>$ & \\
\hline
\end{tabular}

Table 2-1: Categories of $k_{h}$

For tractability in the case with $k_{h} \in\left(\underline{k}_{h}, \bar{k}_{h}\right)$, I impose the following assumption:

\footnotetext{
${ }^{13}$ There are $\bar{d}_{h 1}\left(\frac{1}{2}\right)=2 \int_{s_{1 / 2}}^{+\infty} q\left(s, \frac{1}{2}, k_{h}\right) d F(s)$ and $\bar{d}_{l 1}\left(\frac{1}{2}\right)=2 \int_{-\infty}^{s_{1 / 2}} q\left(s, \frac{1}{2}, k_{l}\right) d F(s)$ The existence and uniqueness of $\bar{k}_{h}$ result from the Intermediate Value Theorem and monotonicity of $\bar{d}_{h 1}\left(\frac{1}{2}\right)-\bar{d}_{l 1}\left(\frac{1}{2}\right)$. The same result applies to $\underline{k}_{h}$ below.

${ }^{14}$ By L'Hospital's rule, there are $\lim _{m \rightarrow 0} \bar{d}_{h 1}(m)=\lim _{m \rightarrow 0} q\left(F^{-1}\left(m+\frac{1}{2}\right), m, k_{h}\right)+\int_{s_{1 / 2}}^{F^{-1}\left(m+\frac{1}{2}\right)} q_{2}\left(s, m, k_{h}\right) d F(s)=$ $q\left(s_{1 / 2}, 0, k_{h}\right)$ and $\lim _{m \rightarrow 0} \bar{d}_{l 1}(m)=\lim _{m \rightarrow 0} q\left(F^{-1}(m), m, k_{l}\right)+\int_{-\infty}^{F^{-1}(m)} q_{2}\left(s, m, k_{l}\right) d F(s)=\lim _{s \rightarrow-\infty} q\left(s, 0, k_{l}\right)$
} 
Assumption 2: For $k_{h} \leq \bar{k}_{h}$, if $m^{1}<m^{2}$, then $\bar{d}_{h 1}\left(m^{2}\right)-\bar{d}_{h 1}\left(m^{1}\right)>\bar{d}_{l 1}\left(m^{2}\right)-\bar{d}_{l 1}\left(m^{1}\right)$.

Assumption 2 is essentially a single crossing condition, stating that for $k_{h} \leq \bar{k}_{h}$, the increase of the same measure of patients will result in a higher increase of the minium mortality rate for the type $k_{h}$ provider than for the type $k_{l}$ provider. The validity of the assumption can be better seen from $k_{h}=k_{l}$, where the assumption essentially means that a provider will face a higher increase of the minimum mortality rate when treating high-severity patients than when treating low-severity patients. Under Assumption 2, the relation between $\bar{d}_{h 1}$ and $\bar{d}_{l 1}$ implied by Table 2-1 can be fully shown in Figure $2-4$. For $k_{h} \in\left(\underline{k}_{h}, \bar{k}_{h}\right)$, denote $\bar{m}\left(k_{h}, k_{l}\right)$ the solution of $\bar{d}_{h 1}(\bar{m})=\bar{d}_{l 1}(\bar{m})$. The fact $\frac{\partial \bar{d}_{h 1}}{\partial k_{h}}<0$ implies that $\frac{\partial \bar{m}}{\partial k_{h}}>0$.

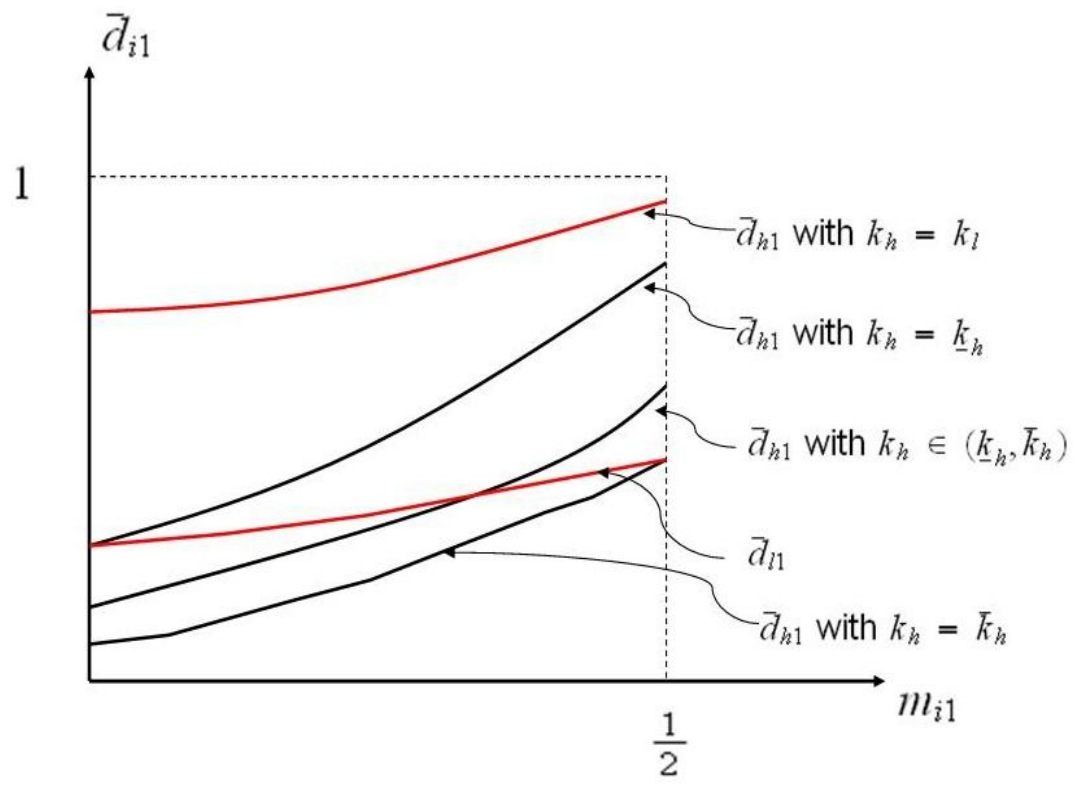

Figure 2-4: Report Card Frontiors of $h$ and $l$

We can now analyze the providers' period 1 equilibrium actions according to the three ranges of $k_{h}$. For simplicity in the subsequent analysis, I further assume that, if a provider engages in selecting patients, the minimum measure of patients that he can avoid is an infinitesimal constant $\varepsilon$.

It is easy to see if $k_{h}>\bar{k}_{h}$ then there exists a separating equilibrium such that $m_{h 1}^{*}=\frac{1}{2}$, because $k_{h}>\bar{k}_{h}$ implies $\bar{d}_{h 1}\left(\frac{1}{2}\right)<\bar{d}_{l 1}\left(\frac{1}{2}\right)$, so the type $k_{h}$ provider can separate himself from the type $k_{l}$ provider by accepting all patients. Similarly, if $k_{h}=\bar{k}_{h}$, then $\bar{d}_{h 1}(m)<\bar{d}_{l 1}(m)$ for all $m<\frac{1}{2}$, so the type $k_{h}$ provider can separate himself from the type $k_{l}$ provider by accepting virtually all patients with shunning $\varepsilon$ measure of patients. 
Now turn to the case where $k_{h}<\bar{k}_{h}$, that is, $\bar{d}_{h 1}\left(\frac{1}{2}\right)>\bar{d}_{l 1}\left(\frac{1}{2}\right)$. First, if $k_{h}<\underline{k}_{h}$, then a necessary condition for a separating equilibrium is that $m_{h 1} \neq m_{l 1}$, since otherwise the fact that $1-M_{h 2}^{*}<\frac{1}{2}$ implies that the type $k_{l}$ provider will have the incentive to mimic the type $k_{h}$ provider's signal. In other words, in a separating equilibrium it must be that the type $k_{h}$ provider generates a signal that the type $k_{l}$ provider does not want to mimic. Due to this, there is a separating equilibrium with

$$
m_{h 1}+\frac{1}{2}=\frac{1}{2}+1-M_{h}^{*}\left(k_{h}, k_{l}\right)
$$

which implies

$$
m_{h 1}=1-M_{h}^{*}\left(k_{h}, k_{l}\right)
$$

In such a separating equilibrium the type $k_{h}$ provider generates a signal that the type $k_{l}$ provider is indifferent to imitate. The type $k_{h}$ provider receives a payoff $m_{h 1}+M_{h}^{*}\left(k_{h}, k_{l}\right)=$ $1>\frac{1}{2}+1-M_{h}^{*}\left(k_{h}, k_{l}\right)$, where the right hand side of the inequality is the payoff if type $k_{h}$ provider accepts all the patients in period 1 and is regarded as a type $k_{l}$ provider in period 2, and so he has no incentive to deviate given the patients' consistent belief, which can be constructed accordingly. Moreover, analogous to the analysis so far, actually every $m_{h 1} \in\left[\frac{3}{2}-2 M_{h}^{*}\left(k_{h}, k_{l}\right), 1-M_{h}^{*}\left(k_{h}, k_{l}\right)\right]$ can be a part of a report card result that the type $k_{l}$ provider does not want to imitate, and so it can also be supported as a part of a separating equilibrium. The one with $m_{h 1}=1-M_{h}^{*}\left(k_{h}, k_{l}\right)$ has the maximum payoff for the providers and so implies the minimum selection behavior.

For $k_{h} \in\left(\underline{k}_{h}, \bar{k}_{h}\right)$, to separate himself from the type $k_{l}$ provider, the type $k_{h}$ provider can choose $m_{h 1}=\bar{m}\left(k_{h}, k_{l}\right)-\varepsilon$, a signal that cannot be imitated by the type $k_{l}$ provider, or $m_{h 1}=1-M_{h}^{*}\left(k_{h}, k_{l}\right)$, a signal that the type $k_{l}$ provider has no incentive to mimic. Since for $k_{h}=\underline{k}_{h}, \bar{m}\left(\underline{k}_{h}, k_{l}\right)=0<1-M_{h}^{*}\left(\underline{k}_{h}, k_{l}\right)+\varepsilon ;$ for $k_{h}=\bar{k}_{h}, \bar{m}\left(\bar{k}_{h}, k_{l}\right)=\frac{1}{2}>1-M_{h}^{*}\left(\bar{k}_{h}, k_{l}\right)+\varepsilon$, and $\bar{m}$ and $M_{h}^{*}$ are increasing in $k_{h}$, there exists a unique $k_{b} \in\left(\underline{k}_{h}, \bar{k}_{h}\right)$ such that $\bar{m}\left(k_{b}, k_{l}\right)=$ $1-M_{h}^{*}\left(k_{b}, k_{l}\right)+\varepsilon$. For $k_{h}<k_{b}, 1-M_{h}^{*}\left(k_{h}, k_{l}\right)>\bar{m}\left(k_{h}, k_{l}\right)-\varepsilon$, so the type $k_{h}$ provider prefers the signal that the type $k_{l}$ provider has no incentive to mimic. For $k_{h} \in\left(k_{b}, \bar{k}_{h}\right)$, $\bar{m}\left(k_{h}, k_{l}\right)-\varepsilon>1-M_{h}^{*}\left(k_{h}, k_{l}\right)$, so the type $k_{h}$ provider prefers the signal that the type $k_{l}$ provider cannot mimic.

The proposition below summarizes the analysis, with the results graphically shown in Figure 2-5. I leave the description of patients' consistent belief system in Appendix.

Proposition 2 If in period 1 the patients let $C$ make the referral decision, there is a separating 
equilibrium such that

$$
m_{h 1}^{*}=\left\{\begin{array}{c}
1-M_{h}^{*}\left(k_{h}, k_{l}\right) \text { if } k_{h} \in\left(k_{l}, k_{b}\right] \\
\bar{m}\left(k_{h}, k_{l}\right)-\varepsilon \text { if } k_{h} \in\left(k_{b}, \bar{k}_{h}\right] \\
\frac{1}{2} \text { if } k_{h}>\bar{k}_{h}
\end{array}\right.
$$

The intuition of Proposition 2 is as follows: When patients let $C$ make the referral decision, the type $k_{h}$ provider faces sicker patients than the type $k_{l}$ provider does, forcing the former to shun sicker patients in order to signal himself. The degree of the type $k_{h}$ provider's selection behavior is characterized by $k_{b}$ and $\bar{k}_{h}$. Intuitively, when $k_{h}=k_{l}$, there is no gain from signaling, and naturally there is no selection behavior in equilibrium. When $k_{h}$ increases, the gain from separating from the type $k_{l}$ provider increases as well, therefore the type $k_{h}$ provider is willing to shun more patients in period 1 in exchange for more patients in period 2. Hence the degree of patient selection initially increases with $k_{h}$. But when $k_{h}>\underline{k}_{h}$, there comes the possibility that the $k_{h}$ provider can generate a signal that cannot be imitated by the type $k_{l}$ provider. However, initially the cost of generating such a signal is larger than generating a signal that the type $k_{l}$ provider does not want to mimic, and so for $k_{h}<k_{b}$, the degree of selection behavior keeps increasing with $k_{h}$. On the other hand, the cost of generating a signal that the type $k_{l}$ provider cannot mimic keeps decreasing with $k_{h}$. The turning point occurs at $k_{h}=k_{b}$, where the costs of the two kinds of signals equal. When $k_{h}$ is larger than $k_{b}$, the type $k_{h}$ provider switches to generating the signal that his counterpart cannot mimic, and consequently the degree of his selection behavior decreases with his type. In the end, when $k_{h}$ is sufficiently high, the type $k_{h}$ provider can signal himself without turning down any patients.

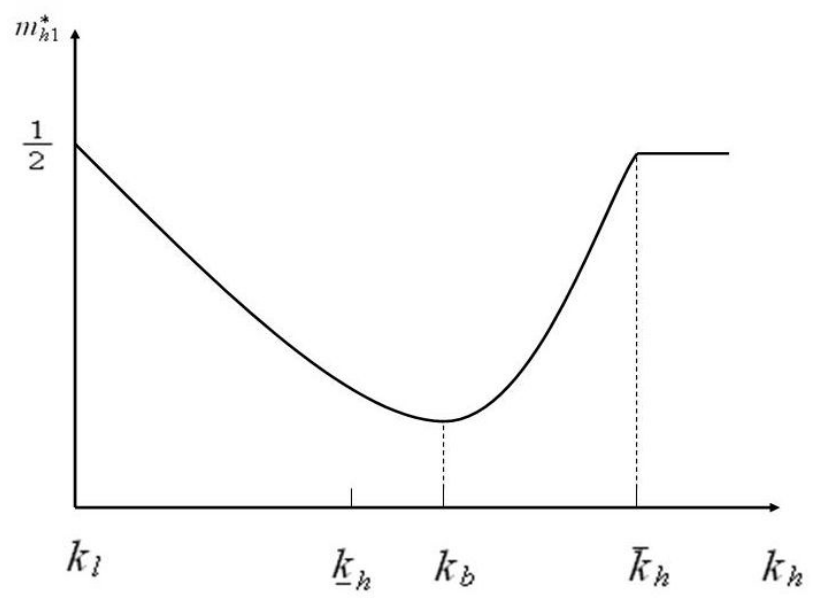

Figure 2-5: $m_{h 1}^{*}$ in the separating equilibrium with $C$ making the period 1 referral decision.

The existence of selection behavior naturally makes one ponder whether there are better 
report mechanisms. In the current setting, however, the answer is no. In general, a report mechanism is a function $R:[0,1] \times[0,1] \rightarrow \Omega[0,1] \times \Omega[0,1]$ where $\Omega[0,1]$ is the $\sigma$-algebra on $[0,1]$. Given $R, r_{i} \in \Omega[0,1] \times \Omega[0,1]$ is the report card of $i$ published to the public at the end of period 1. For example, in the existing report mechanism there is $R\left(m_{i 1}, d_{i 1}\right)=\left(m_{i 1}, d_{i 1}\right)$ with $r_{i}=\left(m_{i 1}, d_{i 1}\right)$. In a PBE induced by a report mechanism $R$, I use $\hat{x}$ to denote the equilibrium value of a variable $x$. Also in a PBE induced by $R$, if $r_{i}=r_{-i}$ then $M_{i 2}\left(r_{i}, r_{-i}\right)=\frac{1}{2}$, as two identical signals yield no new information. A report mechanism $R$ is revealing if $\hat{r}_{l} \neq \hat{r}_{h}$ in an induced PBE, and a revealing report mechanism $R$ is said to cause selection behavior if in equilibrium there is a provider $i$ such that $\hat{m}_{i 1}<\hat{M}_{i 1}$. Similar as the discussion before, if a report mechanism $R$ is revealing, then it must be that in equilibrium $\hat{m}_{l 1}=\frac{1}{2}$.

The following proposition shows that, despite their imperfection in terms of the resulted selection behavior, the existing report cards cause the minimum selection compared with other revealing report mechanisms.

Proposition 3 Among all the revealing report mechanisms, the existing report mechanism $R\left(m_{i 1}, d_{i 1}\right)=\left(m_{i 1}, d_{i 1}\right)$ causes the minimum selection behavior.

Proof. Our previous results imply that we only need to be focused on the scenario where the patients let $C$ make the referral decision in period 1 .

For $k_{h}>\bar{k}_{h}$, we already know that the existing report mechanism causes no selection behavior.

For $k_{h} \leq \bar{k}_{h}$, we only need to focus on the conditions under which the existing report mechanism $R\left(m_{i 1}, d_{i 1}\right)=\left(m_{i 1}, d_{i 1}\right)$ causes selection behavior. Suppose there is a revealing mechanism such that in equilibrium $\hat{m}_{h 1}>m_{h 1}^{*}$. There are two cases:

(i) For $k_{h} \in\left(k_{b}, \bar{k}_{h}\right], m_{h 1}^{*}=\bar{m}\left(k_{h}, k_{l}\right)-\varepsilon$, so

$$
\hat{m}_{h 1} \geq \bar{m}\left(k_{h}, k_{l}\right)>1-M_{h}^{*}\left(k_{h}, k_{l}\right)
$$

which implies

$$
\hat{m}_{h 1}+\frac{1}{2}>\frac{1}{2}+\left[1-M_{h}^{*}\left(k_{h}, k_{l}\right)\right]
$$

then the type $k_{l}$ provider can be better off by deviating to the actions that leads to $r_{l}=\hat{r}_{h}$, which he is capable to do now thanks to the above result $\hat{m}_{h 1}>1-M_{h}^{*}\left(k_{h}, k_{l}\right)$, contradicting the report mechanism being a revealing one.

(ii) For $k_{h} \in\left(k_{l}, k_{b}\right], m_{h 1}^{*}=1-M_{h}^{*}\left(k_{h}, k_{l}\right)$, then $\hat{m}_{h 1}>m_{h 1}^{*}$ implies that

$$
\hat{m}_{h 1}+\frac{1}{2}>\frac{1}{2}+\left[1-M_{h}^{*}\left(k_{h}, k_{l}\right)\right]
$$


then the type $k_{l}$ provider can also be better off by deviating to the actions that leads to $r_{l}=\hat{r}_{h}$, contradicting the report mechanism being a revealing one.

The intuition of Proposition 3 is: In the present setting the existing report cards have shown the maximum information available, and any other revealing mechanisms necessarily temper information based on the existing cards, only to make it easier for the type $k_{l}$ provider to pool with the type $k_{h}$ provider, forcing the the latter to shun even more patients to signal himself. The result therefore suggests that future study aimed at a better report mechanism should be focused on eliciting information beyond the present setting, such as inducing better information about $s_{j}$ and so improving the accuracy of the risk adjustment procedure.

\subsection{Discussion}

Pooling Equilibrium So far the analysis has been focused on separating equilibrium, where the providers' types are revealed by the report cards. However, pooling equilibria also exist, though they involve unappealing off-equilibrium-path patient belief. In a pooling equilibrium, the providers yield the same report card results, keeping the period 2 patients' belief same as the prior, and thus each provider receives measure $\frac{1}{2}$ patients in period 2 . To construct a pooling equilibrium, one only needs to specify an equilibrium report card result with a sufficiently large $m_{i 1}$, and then have the patients hold the belief that any provider unilaterally deviating from that result will be regarded as of type $k_{l}$. However, it follows that to support any pooling equilibrium, the period 2 patients must hold the belief that a provider is of type $k_{l}$ if his report card result is slightly different ${ }^{15}$ from the equilibrium outcome. This is because, if the period 2 patients hold the opposite belief, i.e. a provider will be of type $k_{h}$ should he yield a slightly different report card result, then discontinuity between the period 2 payoff $1 / 2$ from pooling and $M_{h}^{*}\left(k_{h}, k_{l}\right)>1 / 2$ from separating means the type $k_{h}$ provider will always slightly deviate in period 1 . But such a belief system implies that the patients prefer not to distinguish the high quality provider from the low quality one, which is implausible.

$C$ 's Referring Pattern More generally we can characterize $C$ 's referring pattern by a cutoff level $s_{c}$, which can be larger or smaller than $s_{1 / 2}$. Above $s_{c}, C$ refers a patient to the type $k_{h}$ provider, and otherwise refers her to the type $k_{l}$ provider. For simplicity let's focus on the case where patients let $C$ make the decision in period 1 . If $s_{c}>s_{1 / 2}$ then the previous analysis carries through. The type $k_{h}$ provider's report card frontier is similarly characterized by three

\footnotetext{
${ }^{15}$ More exactly, "slightly different" means the report card result is $\varepsilon$ away from the the equilibrium outcome.
} 
ranges of $k_{h}$, with $\underline{k}_{h}$ unchanged while $\bar{k}_{h}$ being lower than before due to a lower measure of coming patients. Differently, if $s_{c}<s_{1 / 2}$, then in any scenario the report cards will reveal the providers' types without causing patient selection. This is because the type $k_{h}$ provider is now receiving more coming patients than the type $k_{l}$ provider, and so by accepting all the patients he will generate a report card with $m_{h 1}=1-F\left(s_{c}\right)$ that can not be imitated by the type $k_{l}$ provider. Nonetheless, I should point out that throughout the analysis on separating equilibrium I have put no restriction on patients' off-equilibrium-path belief, as long as the belief system supports the equilibrium strategies. It will not be unrealistic to assume that the patient's belief system is characterized by "indifference curves" such that a provider with a report card result on a lower indifference curve (lower mortality rate and higher volume) will be regarded as the type $k_{h}$ provider. Given any of such belief systems, the type $k_{h}$ provider's incentive to signal himself from selecting patients revives.

Furthermore, the benchmark case allows us to investigate different specifications of $C$ 's referring pattern. First, suppose in contrast $C$ refers healthier patients to the type $k_{h}$ provider and sicker patients to the type $k_{l}$ provider, characterized by the cutoff level $s_{1 / 2}$. Then given any measure of surgical patients the minimum mortality rate of the type $k_{l}$ provider will be higher than that of the type $k_{h}$ provider, which is analogous to the benchmark case. Consequently, the report cards will reveal the providers' types without causing providers to select patients. Second, suppose $C$ does not know the providers' types. Then it is natural to assume that $C$ will refer patients to the providers with equal probabilities, which leads us back to the benchmark case.

Payoff from the Alternative Treatment For simplicity I have assumed 0 payoff for patients undergoing the alternative treatment, which captures the worst possible scenario should providers engage in selection. The set-up could be more realistic. For example, assume a patient's payoff from receiving the alternative treatment is $\alpha \in(0,1)$, then the patients' period 1 expected payoffs are, for $i \in\{A, B\}$,

$$
\begin{aligned}
E_{i 1}= & \left.\frac{1}{2} \int_{\sigma_{i 1}\left(k_{l}\right)} 1-q\left(s, m_{l 1}, k_{l}\right) d F(s)+\frac{1}{2} \int_{\sigma_{i 1}\left(k_{h}\right)} 1-q\left(s, m_{h 1}, k_{h}\right) d F(s)\right] \\
& +\alpha\left[1-\frac{1}{2}\left(\int_{\mathbf{R} \backslash \sigma_{i 1}\left(k_{l}\right)} d F(s)+\int_{\mathbf{R} \backslash \sigma_{i 1}\left(k_{h}\right)} d F(s)\right)\right]
\end{aligned}
$$


and

$$
\begin{aligned}
E_{C 1}= & \int_{\sigma_{i 1}\left(k_{l}\right) \cap\left(-\infty, s_{1 / 2}\right)} 1-q\left(s, m_{l 1}, k_{l}\right) d F(s)+\int_{\sigma_{i 1}\left(k_{h}\right) \cap\left(s_{1 / 2},+\infty\right)} 1-q\left(s, m_{h 1}, k_{h}\right) d F(s) \\
& +\alpha\left[1-\int_{\mathbf{R} \backslash \sigma_{i 1}\left(k_{l}\right) \cup \sigma_{i 1}\left(k_{h}\right)} d F(s)\right]
\end{aligned}
$$

$\alpha \in(0,1)$ implies the alternative treatment yields a positive payoff lower than a successful surgery. Such a generalization captures several facts. First, a standard alternative treatment, percutaneous transluminal coronary angioplasty (PTCA), is known to suffer from recurrence of symptoms. The reported failure rates due to restenosis (recurrent narrowing) in the first 612 months following the PTCA procedure are 30-60\%. (Rupprecht, et al. 2005; Kulick, 2005). Second, an alternative treatment may mean transferring patients to other providers that are not subject to the report cards, including those in the neighbor states (Omoigui et al. 1996) and those within-state government hospitals, including county and city hospitals ${ }^{16}$. However, I believe my results are robust under the original assumption, and in terms of theoretical analysis the generalization will offer no more insights but computational redundancy. This is because, first, the patients' decisions will be similar as in the 0 payoff setting: In period 2, a patient will still choose the provider that gives her the highest expected payoff, and in period 1 the patients will equally randomize between the providers when there are no $C$, or when $C$ is in action choose between self-referral and $C$ in the way analogous to the 0 payoff setting. Given such similarity in patients' actions and response to report cards, providers' actions should also be close to the original setting.

More than Two Periods While the two-stage game I employ helps us gain insights of the effects of the report cards in a simple setting, in reality there may be more than two periods. When there are multiple periods, they can be broken into two categories that are represented by the two stages in my model: the signaling periods and the signaled periods. In the latter periods, since the providers' types are revealed, the strategic interaction between providers and patients in each period will coincide with the second period in the two-stage game. The earlier periods, however, may differ from the original model, because adding more periods implies that the type $k_{l}$ provider has more incentive to imitate the high-quality provider. An immediate consequence is that $k_{b}$ will be lower than before since the type $k_{h}$ provider's cost of generating a signal that the type $k_{l}$ provider does not want to imitate is now higher. Moreover, for $k_{h}<\underline{k}_{h}$, a higher payoff from pooling with the type $k_{h}$ provider due to adding

\footnotetext{
16 "In large urban areas, these tend to be safety net hospitals (serving the poor and uninsured)." Raffel \& Barsukiewicz, "The U.S. Health System, Origins and Functions", 5th Edition, page 128
} 
more periods means that the type $k_{l}$ provider may imitate any report card results from the type $k_{h}$ provider, resulting in pooling in early periods. Nonetheless, aiming at a one-signalingperiod equilibrium, we can realistically introduce a discount factor, which discounts future payoffs but for simplicity has been assumed away in the two-stage game.

Word-of-Mouth Other than resorting to published information, patients may rely on word-of-mouth from friends and relatives to gain information about the providers (Gibbs et al., 1996). Though such information is inevitably noisy, if it is positively correlated with a provider's quality, we may conjecture that existence of word-of-mouth alleviates the selection behavior, since it provides the providers with another channel to signal their types. In particular, if one assumes that patients suffering from failed surgeries (death) do not engage in spreading provider information, then the larger the amount of successful surgeries, the larger the good word-of-mouth. A caution, however, is that the trade-off between $m_{i 1}$ and $\bar{d}_{i 1}$ implies that the measure of successful surgeries, $m_{i 1}\left(1-\bar{d}_{i 1}\right)$, may not achieve its maximum at $m_{i 1}=M_{i 1}$, and so requires more careful specification and analysis.

Previous studies also show that, compared with a small town with a small number of providers, it is harder for patients to gain information about providers through word-of-mouth in a big city with a large number of providers, since the chance that friends and relatives know a randomly picked provider is low (Satterthwaite, 1979; Pauly and Satterthwaite, 1981). Following this line, I conjecture that providers' selection behavior will be more severe in urban areas than in suburban and rural areas. In other words, selection will be most severe in the areas where report cards are needed the most. Future extension in this direction bears both theoretical and empirical interests.

Learning-by-Doing Existence of learning-by-doing among providers has also been documented in empirical study (Ramanarayanan, 2006). Since I assume provider types to be numerical rather than categorical, the model can be further extended to incorporate learningby-doing. A starting point can be assuming the increment of provider quality $\Delta k_{i}$ to be an increasing function of $m_{i 1}$, and so the provider's period 2 quality increases with the measure of patients he treats in period 1 . Consequently, upon seeing the report cards, period 2 patients now will figure out not only $k_{i}$ but also $k_{i}+\Delta k_{i}\left(m_{i 1}\right)$. Then we may conjecture that learning-by-doing will attenuate the selection behavior, since a provider is now facing a second layer of trade-off: Though avoiding patients can help to signal oneself or pool with the other, it also lowers $\Delta k_{i}$. In extreme cases, it may be that $k_{l}+\Delta k_{l}\left(m_{l 1}\right)>k_{h}+\Delta k_{h}\left(m_{h 1}\right)$, that is, the type $k_{l}$ provider grows up to be a provider with higher quality. The concern of lowered $\Delta k_{i}$ therefore should curb a provider's incentive to avoid patients. 


\section{Empirical Implications, Framework, and Circumstan- tial Evidence}

\subsection{Effects of Report Cards}

In general, the theoretical model implies that effects of the existing report cards, including incidence effect, quantity effect, matching effect, and welfare effect, all vary from period 1 to period 2. Throughout this section I will focus on the scenario where $C$ makes the referral decision. Without loss of generality, I further restrict the attention to the generic cases of $\tilde{M}_{h}^{*}>\bar{M}_{h}^{*}$ and $\tilde{M}_{h}^{*}<\bar{M}_{h}^{*}$.

Incidence Effect and Quantity Effect Following the notion in Dranove et al. (2003), the incidence effect of report cards is measured by the average change of illness severity of the patients receiving the surgery, compared with when there are no report cards. At period 1 , since the type $k_{l}$ provider accepts all patients whereas the type $k_{h}$ provider engages in selection behavior when $k_{h}<\bar{k}_{h}$, the report cards lead to a negative incidence effect. At period 2, however, the incidence effect depends. If $\tilde{M}_{h}^{*}>\bar{M}_{h}^{*}$, then in addition to treating all the patients with $s_{j} \geqslant s_{1 / 2}$ the type $k_{h}$ provider also treats a fraction of patients with $s_{j}<s_{1 / 2}$, which lowers the mean illness severity of his patients, and thus leads to a negative incidence effect. If $\tilde{M}_{h}^{*}<\bar{M}_{h}^{*}$ then the type $k_{h}$ provider treats all the patients with $s_{j}<s_{1 / 2}$ plus a fraction of patients with $s_{j} \geqslant s_{1 / 2}$, leading to a lower mean illness severity of his patients. In contrast, the type $k_{l}$ provider now only treats patients with $s_{j} \geqslant s_{1 / 2}$, resulting in a higher mean illness severity for him. Consequently the average incidence effect is unclear.

The quantity effect is measured by the average change of the measure of the patients undergoing the surgery, compared with when there are no report cards. At period 1, the type $k_{h}$ provider's selection behavior implies a negative quantity effect. At period 2, as the providers' types are revealed, the type $k_{h}$ provider sees an increase of patients while the type $k_{l}$ provider's patient measure decreases. Since both providers accept all the patients, on average the effects on the two cancel out, implying a zero quantity effect in period 2. In reality, however, providers' selection behavior entails a prolonged decision process, implying not only denial of surgery but also delayed treatments. Moreover, recurring symptoms from the alternative treatment such as PTCA $^{17}$ also implies an increase of patients in the 2nd period. Based on these I predict a positive quantity effect in period 2.

The theoretical model's implication about incidence effects and quantity effects allows us to visit the conclusions drawn by Dranove et al. (2003) with a second thought. Taking a

\footnotetext{
${ }^{17}$ (Rupprecht, et al. 2005; Kulick, 2005)
} 
difference-in-differences approach, they show that releasing CABG report cards in New York and Pennsylvania resulted in negative incidence effects and positive quantity effects. They argue that the negative incidence effect indicates "report cards have caused a shift in incidence from sicker to healthier patients", and the positive quantity effect in addition implies that "the quantity increase was entirely accounted by surgeries on less severely ill patient". But based on my model, these results should be interpreted more carefully. First, a negative incidence effect alone can not be used to indicate existence of selection behavior. As aforementioned, in the theoretical model in period 2 there is no selection behavior, but when $\tilde{M}_{h}^{*}>\bar{M}_{h}^{*}$, the shift of the fraction of patients with $s_{j}<s_{1 / 2}$ from the type $k_{l}$ provider to the type $k_{h}$ provider also leads to a negative incidence effect. Second, a negative incidence effect together with a positive quantity effect does not mean that the quantity increase is attributed to increase of surgeries on healthier patients. More exactly, in Dranove et al. (2003), the notion that the increase of quantity came from increase of surgeries on healthier patients implicitly assume that the providers can shift the distribution of CABG patient's illness severity toward a lower mean. Such an assumption is self-contradictory, because if the providers are capable of shifting the distribution of patients' illness severity, then the providers will not be short of patient sources, which implies they will not be concerned by the report cards, and consequently they will not select patients in the first place. In my model, selection behavior exists in the first period, but it is associated with a negative incidence effect and a negative quality effect. Therefore, to indicate existence of selection behavior, empirically one needs to show both effects to be negative in the first period.

Matching Effect The matching effect is measured by the average change in the variation of illness severity in the surgical patients. Though Dranove et al. (2003) measures variation by the coefficient of variation, in the context of my model variance is a more accurate measure since it is exempted from the influence of mean. In the model, in period 1, the type $k_{h}$ provider's avoidance of sicker patients implies a smaller variance of patient types, thus a negative matching effect. But the effect in period 2 depends. If $\tilde{M}_{h}^{*}>\bar{M}_{h}^{*}$, then the distribution of patient types confronting the type $k_{l}$ provider does not change, whereas the type $k_{h}$ provider faces both sicker patients and healthier patients, implying a larger variance (also a higher coefficient of variation due to a lower mean), resulting in a positive matching effect. If $\tilde{M}_{h}^{*}<\bar{M}_{h}^{*}$, the average effect is uncertain, since on one hand the type $k_{l}$ provider only treats patients with $s_{j} \geqslant s_{1 / 2}$, and thus the actual effect depends on comparison between $\operatorname{Var}\left(s \mid s<s_{1 / 2}\right)$ and $\operatorname{Var}\left(s \mid s \geq s_{1 / 2}\right)$, and on the other hand, since the type $k_{h}$ provider treats all types of patients, the matching effect on the type $k_{h}$ provider is positive due a higher variance (also a higher coefficient of variation due to a lower mean). Nevertheless one message is clear: As 
discussed in the previous section, the theoretical model challenges the conventional wisdom that revelation of provider types will result in only sicker patients being matched with the high-quality provider, since all patients, healthier or sicker, would like to seek the best possible treatment. In line with this, a negative period 1 matching effect now is a piece of evidence supporting existence of selection behavior, instead of indication of "improved patient sorting" as suggested in Dranove et al. (2003).

Welfare Effect Social welfare in each period is measured by the sum of payoffs of providers and patients. When there are no report cards, the social welfare, denoted by $W_{N R}$, is the same in each period:

$$
W_{N R}=1+\left[1-\left[\int_{-\infty}^{s_{1 / 2}} q\left(s, \frac{1}{2}, k_{l}\right) d F(s)+\int_{s_{1 / 2}}^{+\infty} q\left(s, \frac{1}{2}, k_{h}\right) d F(s)\right]\right]
$$

When there are report cards, the social welfare in the first period, denoted by $W_{R 1}$, is

$$
\begin{aligned}
W_{R 1} & =\left(\frac{1}{2}+m_{h 1}^{*}\right)+\left[\int_{-\infty}^{s_{1 / 2}} 1-q\left(s, \frac{1}{2}, k_{l}\right) d F(s)+\int_{s_{1 / 2}}^{F_{h 1}^{-1}\left(m_{h 1}^{*}\right)} 1-q\left(s, m_{h 1}^{*}, k_{h}\right) d F(s)\right] \\
& =\frac{1}{2}+2 m_{h 1}^{*}-\left[\int_{-\infty}^{s_{1 / 2}} q\left(s, \frac{1}{2}, k_{l}\right) d F(s)+\int_{s_{1 / 2}}^{F_{h 1}^{-1}\left(m_{h 1}^{*}\right)} q\left(s, m_{h 1}^{*}, k_{h}\right) d F(s)\right]
\end{aligned}
$$

and the the social welfare in the second period, denoted by $W_{R 2}$, depends. If $\tilde{M}_{h}^{*}>\bar{M}_{h}^{*}$, then

$$
\begin{aligned}
W_{R 2}= & +1-\left\{\left(\bar{M}_{h}^{*}-\frac{1}{2}\right) \int_{-\infty}^{s_{1 / 2}} q\left(s, \bar{M}_{h}^{*}, k_{h}\right) d F(s)+\left(1-\bar{M}_{h}^{*}\right) \int_{-\infty}^{s_{1 / 2}} q\left(s, 1-\bar{M}_{h}^{*}, k_{l}\right) d F(s)\right. \\
& \left.+\frac{1}{2} \int_{s_{1 / 2}}^{+\infty} q\left(s, \bar{M}_{h}^{*}, k_{h}\right) d F(s)\right\}
\end{aligned}
$$

and if $\tilde{M}_{h}^{*}<\bar{M}_{h}^{*}$,

$$
\begin{aligned}
W_{R 2}= & 1+1-\left\{\left(\tilde{M}_{h}^{*}-\frac{1}{2}\right) \int_{s_{1 / 2}}^{+\infty} q\left(s, \tilde{M}_{h}^{*}, k_{h}\right) d F(s)+\left(1-\tilde{M}_{h}^{*}\right) \int_{s_{1 / 2}}^{+\infty} q\left(s, 1-\tilde{M}_{h}^{*}, k_{l}\right) d F(s)\right. \\
& \left.+\frac{1}{2} \int_{-\infty}^{s_{1 / 2}} q\left(s, 1-\tilde{M}_{h}^{*}, k_{h}\right) d F(s)\right\}
\end{aligned}
$$

The welfare effect is then measured by the sum of both periods' effects, $\left(W_{R 1}-W_{N R}\right)+$ $\left(W_{R 2}-W_{N R}\right)$. The actual result, however, is not clear and stands for empirical tests. However, it is worth pointing out that in each period report cards lead to not only welfare losses but 
also gains. In period 1, on one hand avoidance of patients leads to decreased payoff for both the type $k_{h}$ provider and the patients denied surgery; on the other hand, a decreased patient volume improves the type $k_{h}$ provider's outcome, benefiting the patients that do receive surgeries from him. In period 2 , if $\tilde{M}_{h}^{*}>\bar{M}_{h}^{*}$, then all the patients with $s_{j}<s_{1 / 2}$ will benefit from those switching to the type $k_{h}$ provider, but the type $k_{h}$ provider now faces an increased patient volume, lowering the payoffs of those with $s_{j} \geq s_{1 / 2}$. Similarly, if $\tilde{M}_{h}^{*}<\bar{M}_{h}^{*}$, all the patients with $s_{j}<s_{1 / 2}$ benefit from receiving surgeries from the type $k_{h}$ provider, but the large amount of patients drives a fraction of patients with $s_{j} \geq s_{1 / 2}$ to choose the type $k_{l}$ provider, and thus lowers their payoffs.

\subsection{Empirical Framework}

The discussion in the previous subsection shows that based on the theoretical model each effect of the existing report cards varies from period 1 to period 2. As a result, a differencein-differences estimate should be used for each treatment effect in each period. On the other hand, the traditional single difference-in-differences estimate only captures the average of the two periods' effects. To see these, let time period $t=0,1,2$, where 0 stands for the period before the report-card program is effective, with 1 for the first period and 2 for the second. Denote the superscript $T$ the treatment group and NT the control (non-treatment) group. Denote $y$ a variable whose change from $t=0$ to $t=1,2$ in the treatment group encompasses a treatment effect of interest. Suppose there are $n$ members in the treatment group and $m$ members in the control group. For simplicity, ignore covariates.

Suppose

$$
\begin{array}{ll}
y_{j 0}^{T}=\alpha_{0}+\varepsilon_{j 0}, & y_{j^{\prime} 0}^{N T}=\alpha_{0}+\varepsilon_{j^{\prime} 0} \\
y_{j 1}^{T}=\alpha_{1}+\beta_{1}+\varepsilon_{j 1}, & y_{j^{\prime} 1}^{N T}=\alpha_{1}+\varepsilon_{j^{\prime} 1} \\
y_{j 2}^{T}=\alpha_{1}+\beta_{2}+\varepsilon_{j 2}, & y_{j^{\prime} 2}^{N T}=\alpha_{1}+\varepsilon_{j^{\prime} 2}
\end{array}
$$

where $\varepsilon_{j t}$ and $\varepsilon_{j^{\prime} t}$ are i.i.d. with $E\left[\varepsilon_{j t}\right]=0$. Then there are

$$
\begin{array}{ll}
E\left[y_{0}^{T}\right]=\alpha_{0}, & E\left[y_{0}^{N T}\right]=\alpha_{0} \\
E\left[y_{1}^{T}\right]=\alpha_{1}+\beta_{1}, & E\left[y_{1}^{N T}\right]=E\left[y_{2}^{N T}\right]=\alpha_{1} \\
E\left[y_{2}^{T}\right]=\alpha_{1}+\beta_{2}, &
\end{array}
$$

and identification of the period 1 effect $\beta_{1}$ and the period 2 effect $\beta_{2}$ stems from

$$
\begin{aligned}
& \beta_{1}=\left[E\left[y_{1}^{T}\right]-E\left[y_{0}^{T}\right]\right]-\left[E\left[y_{1}^{N T}\right]-E\left[y_{0}^{N T}\right]\right] \\
& \beta_{2}=\left[E\left[y_{2}^{T}\right]-E\left[y_{0}^{T}\right]\right]-\left[E\left[y_{2}^{N T}\right]-E\left[y_{0}^{N T}\right]\right]
\end{aligned}
$$


On the other hand the single difference-in-differences estimate $\hat{\beta}$ implies

$$
\begin{aligned}
\hat{\beta}= & {\left[\frac{\sum y_{j 1}^{T}+\sum y_{j^{2}}^{T}}{2 n}-\frac{1}{n} \sum y_{j 0}^{T}\right]-\left[\frac{\sum y_{j^{\prime} 1}^{N T}+\sum y_{j^{\prime} 2}^{N T}}{2 m}-\frac{1}{m} \sum y_{j^{\prime} 0}^{N T}\right] } \\
= & {\left[\frac{1}{2}\left[\frac{\sum y_{j 1}^{T}}{n}+\frac{\sum y_{j 2}^{T}}{n}\right]-\frac{1}{n} \sum y_{j 0}^{T}\right]-\left[\frac{\sum y_{j^{\prime} 1}^{N T}+\sum y_{j^{\prime} 2}^{N T}}{2 m}-\frac{1}{m} \sum y_{j^{\prime} 0}^{N T}\right] } \\
& \underset{p}{\frac{1}{2}}\left\{\left[\left(E\left[y_{1}^{T}\right]+E\left[y_{2}^{T}\right]\right)-2 E\left[y_{0}^{T}\right]\right]-2\left[E\left[y_{1}^{N T}\right]-E\left[y_{0}^{N T}\right]\right]\right\} \\
= & \frac{1}{2}\left(\beta_{1}+\beta_{2}\right)
\end{aligned}
$$

An important implication of (1) is that the single difference-in-differences estimate cannot capture the long-run welfare effect with short run data, while estimating the welfare effect once every period can do so. In the theoretical model, two stages suffice for the analysis, but in reality there may be more than one period after provider types are revealed. To count the actual welfare effect, one needs sum up the (discounted) effects in all periods. Consequently, even though a negative period 1 effect may outweigh a positive period 2 effect, leading to a negative single difference-in-differences estimation result, the sum of all periods' effects may still be positive, rendering the single difference-in-differences result inconclusive. A simple example is as follows: Suppose in total there are 4 periods, with the first period's welfare effect being -3 , and the others being 2 . Thus the actual welfare effect is 3 . Suppose one only has data of the first two periods, then the single difference-in-differences estimation will lead to -0.5 , the average of the first two periods' effects, which is a misleading. In contrast, separately estimating the first two periods' effects allows us to capture -3 and 2, and consequently capture the long run welfare effect.

Moreover, based on this once-every-period framework, we need a more careful handling of the data set in Dranove et al. (2003). The data set covers data from 1987 to 1994. However, the report-card program was introduced in New York in 1991 but was not enacted in Pennsylvania until 1993. Hence, in the context of the theoretical model, the data set contains both period 1 and period 2 data for New York, but only contains period 1 data for Pennsylvania. Therefore, assuming each period consists of two years, to estimate $\beta_{1}$, one needs to exclude the 1993-94 New York data, while to estimate $\beta_{2}$ one needs to exclude the 1991-92 New York data and the 1993-94 Pennsylvania data.

To estimate each treatment effect, the specification of the regression is the same as that in Dranove et al. (2003) except that now there are two difference-in-differences estimates for 
each effect. To test for incidence effects, the regression form is

$$
\ln \left(h_{l s t}\right)=\mathbf{A}_{s}+\mathbf{B}_{t}+g \cdot \mathbf{Z}_{l s t}+p \cdot L_{s t}+q \cdot N_{s t}+e_{l s t}
$$

where $l$ indexes hospitals, $s$ indexes states, and $t$ indexes time, $t=1987, \ldots, 1994 ; h_{s t}$ is the mean of the illness severity before admission or treatment of hospital l's elderly Medicare CABG patients; $\mathbf{A}_{s}$ is a vector of state fixed effects; $\mathbf{B}_{t}$ is a vector of time fixed effects; $\mathbf{Z}_{l s t}$ is a vector of hospital characteristics. $N_{s t}$ is the number of hospitals, and its square and cube, in state $s$ at time $t$; and $e_{l s t}$ is an error term. In the first estimate, where the data set excludes the 1993-94 New York data, $L_{s t}=1$ if the hospital is in New York in 1991 or 1992, or in Pennsylvania in or after 1993. In the second estimate, where the data set excludes the 1991-92 New York data and the 1993-94 Pennsylvania data $L_{s t}=1$ if the hospital is in New York in or after 1993. The coefficient $p$ is the difference-in-differences estimate of the effect of report cards on the severity of patients who receive CABG. To estimate the matching effect, the dependent variable will be replaced by the within-hospital coefficient of variation of illness severity.

To estimate quantity effects, the regression form is

$$
C_{k s t}=\mathbf{A}_{s}+\mathbf{B}_{t}+g \cdot \mathbf{Z}_{k s t}+p \cdot L_{s t}+e_{k s t}
$$

where $k$ indexes patients, $s$ indexes states, and $t$ indexes time, $t=1987, \ldots, 1994 ; C_{k s t}$ is a binary variable equal to one if patient $k$ from state $s$ at time $t$ received CABG surgery within one year of admission to the hospital for acute myocardial infarction (AMI); $\mathbf{A}_{s}$ is a vector of sate fixed effects; $\mathbf{B}_{t}$ is a vector of time fixed effects; $\mathbf{Z}_{k s t}$ is a vector of patient characteristics; and $e_{k s t}$ is an error term. Similar as in the previous regression form, in the first estimate, where the data set excludes the 1993-94 New York data, $L_{s t}=1$ if the hospital is in New York in 1991 or 1992, or in Pennsylvania in or after 1993. In the second estimate, where the data set excludes the 1991-92 New York data and the 1993-94 PA data $L_{s t}=1$ if the hospital is in New York in or after 1993. A positive $p$ implies that report cards increased the probability that an AMI patient receives CABG.

My empirical framework also calls for a more careful choice of the control group states. As I discuss in Section 2, as a means of avoiding patients, the providers in New York and Pennsylvania may transfer sicker patients to the neighbor states (Omoigui et al., 1996), taking resources that otherwise would be allocated to the neighbor states' own patients. Hence the report-card programs may affect those neighbor states in the first period. Moreover, in period 2, although the report cards only contain statewide provider information, their free 
accessibility means that their readers are not restricted to the issuing states. The argument in the theoretical model that period 2 patients prefer informed self-referral then implies that, further taking into account the sizes and closeness of the northeastern states around New York and Pennsylvania, patients in the neighbor states may travel to the issuing states for informed treatment. Hence the report-card programs may also have an impact on the neighbor states in the second period. ${ }^{18}$ Therefore, to select the control group members, I propose to first use the states adjacent to New York and Pennsylvania as the treatment group, and use the others excepts New York and Pennsylvania as the control group. If a treatment effect on the neighbor states is significant, then the neighbor states should be excluded from the control group for the estimation on New York and Pennsylvania.

\subsection{Data and Circumstantial Evidence}

Dranove et al. (2003) use data from two sources. The patient-level data are the longitudinal Medicare claim data for individual elderly beneficiaries who were admitted to a hospital either with a new primary diagnosis of AMI or for CABG surgery from 1987 to 1994. The hospitallevel data come from the American Hospital Association.

Despite inaccessibility of the data set at this stage, ${ }^{19}$ particular specifications in Dranove et al. (2003) allow us to reinterpret their estimation results, offering circumstantial evidence for my theoretical predictions. Citing an augment of the New York report cards in 1992, Dranove et al. (2003) estimate each treatment effect under two assumptions: one that assumes report cards effective 1991 in New York, another assuming them effective 1993 in New York. Though the 1992 augment was to include surgeon-level information, the 2003 paper is focused on the hospital level. Hence the augment should have small effects on the hospitals. As discussed earlier, in the single difference-in-differences estimation, blending both periods' data mixes the treatment effect of one period with that of another. Since under the 1993 assumption period 1 New York data are excluded from the report-cards-in-effect data, a period 2 effect will be more significant in the regression under the 1993 assumption.

Before investigating the differences between the estimates under the two assumptions, however, we should note that the significance of the differences will be weakened by the fact that the report-cards-in-effect data under the 1993 assumption still contain period 1 data in Pennsylvania. Therefore, as to be seen, though the difference between estimates for a welfare

\footnotetext{
${ }^{18}$ Such an impact also lowers income for the providers in the neighbor states, which may help to explain why ensuing states releasing report cards are initially centered around New York.

${ }^{19}$ As one of the authors in the 2003 paper points out in a correspondence to this paper's author:"[b]ecause the data have information on particular individuals, it is subject to strict confidentiality restrictions including that we can't provide it to anyone else. You can apply to use the data if you like, although it is a long process."
} 
effect is significant, the differences between other estimates are not. Moreover, the selection of the control group members in the 2003 paper do not follow the empirical framework in this paper. Hence the differences between estimates under the two assumptions in the 2003 paper, though consistent with my theory, remain circumstantial evidence.

First, Dranove et al. (2003) measure the welfare effect of report cards by the change of patient's post-surgery hospital expenditure and readmission rates, and they conclude that overall report cards decreased social welfare. ${ }^{20}$ The estimation results for post-surgery hospital expenditure, reproduced in Table 3-1, show that the post-surgery hospital expenditure for the sicker patients (those with a prior year's inpatient admission) increased significantly under the 1991 assumption, but the change was insignificant under the 1993 assumption. Since the estimation under the 1993 assumption uses not only period 2 New York data but also period 1 Pennsylvania data as the data after the policy is effective, the comparison indicates that the period 1 effect on sicker patients' post-surgery hospital expenditure is positive while the period 2 effect is negative. In other words, revelation of providers' types decreases sicker patients' post-surgery expenditure, contributing to a positive welfare effect. As discussed earlier, since in reality there may be more than one period after revelation of providers' types, even if a negative period 1 welfare effect outweighs a positive period 2 effect, the overall welfare effect may still be positive.

\begin{tabular}{|c|c|c|}
\hline \multicolumn{3}{|c|}{$\begin{array}{l}\text { EFFECTS OF REPORT CARDS ON HOSPITAL EXPENDITURES: MEDICARE BENEFICIARIES WTH AMI, } \\
1987-94\end{array}$} \\
\hline & $\begin{array}{c}\text { A. ASSUMES REPORT CARDS } \\
\text { EFFECTIVE } \\
1991 \text { IN N.Y. AND } 1993 \text { IN PA }\end{array}$ & $\begin{array}{c}\text { B. ASSUMES REPORT CARDS } \\
\text { EFFECTIVE } \\
1993 \text { IN N.Y AND PA. }\end{array}$ \\
\hline DEPENDENT VARIAELE & $\begin{array}{l}\text { Report Cards } x \text { Prior } Y \text { ear Admission } \\
\text { (3) }\end{array}$ & $\begin{array}{l}\text { Report Cards } x \text { Prior Year Admission } \\
\text { (6) }\end{array}$ \\
\hline $\begin{array}{l}\text { In (total hospital expenditures in } \\
\text { year after admission) }\end{array}$ & $\begin{array}{c}3.35^{*} \\
(-1.75)\end{array}$ & $\begin{array}{c}1.93 \\
(-1.49)\end{array}$ \\
\hline
\end{tabular}

* Significantly different from 0 at the 10 percent level

Reproduced from Dranove et al. (2003) Table 5

Table 3-1

Second, as discussed before, I predict quantity effects to be negative in period 1 and positive

\footnotetext{
${ }^{20}$ Though these post-surgery measures are not incorporated in my theoretical model, the implication on other treatment effects suggests that these measures should also vary across the periods, and thus should be estimated separately. If both measures turn out to be positive (i.e. higher expense, higher readmission rates) on both periods, then we can conclude that the report cards resulted in lower social welfare. In other cases, however, the results need more careful interpretation.
} 
in period 2. Thus the difference-in-differences estimate under the 1993 assumption should be larger than that under the 1991 assumption. The results in the 2003 paper, reproduced in Table 3-2, are consistent with this prediction. The increase of probability that the average AMI patient will undergo CABG surgery within one year of admission for AMI rises from 0.60 under the 1991 assumption to 0.91 under the 1993 assumption. The result also shows that in the single difference-in-differences estimate the positive period 2 effect outweighs the negative period 1 effect, more so under the 1993 assumption.

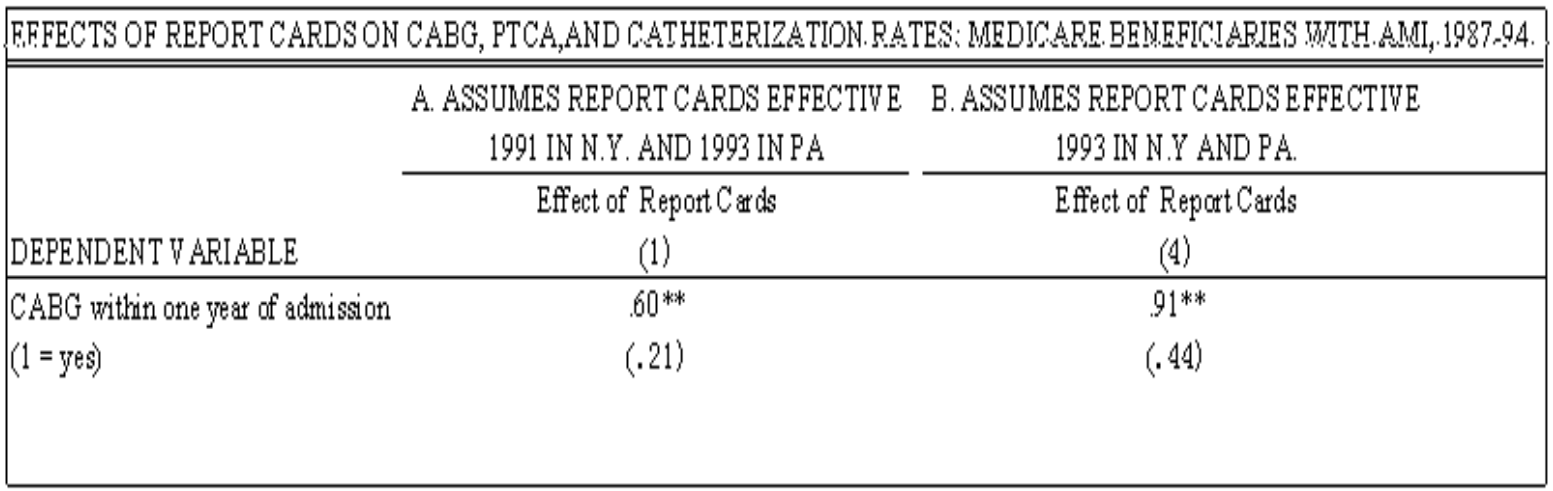

** Significantly different from 0 at the 5 percert level Reproduced from Dranove et al. (2003) Table 4

Table 3-2

In addition to comparing the estimates under the 1991 and 1993 assumptions, my theoretical results also allow us to reinterpret some regression results in the 2003 paper regardless of the assumptions on effective years. Based on an implicit assumption of identical patient distribution between providers, Dranove et al. (2003) interpret a report-card-induced improved matching between patients and providers as one that leads to sicker patients matched with high-quality providers and healthier patients matched with low-quality ones, suggesting a negative period 2 matching effect. In contrast, as discussed before, the theoretical model suggests that the period 2 incidence effect tends to be positive. Though the positive estimation results in the 2003 paper, reproduced in Table 3-3, do not directly support the claim made by Dranove et al., the numbers are consistent with mine. Since the estimates mix the period 1 effect with the period 2 effect, and the period 1 matching effect is negative due to the selection behavior, the positive results imply a positive period 2 matching effect, which is more significant under the 1993 assumption. 


\begin{tabular}{|c|c|c|}
\hline \multicolumn{3}{|c|}{$\begin{array}{l}\text { EFFECTS OF REPORT CARDS ON THE WTHIN-HOSPITAL COEFFICIENT OF VARIATION } \\
\text { AND MEAN OF PATIENTS HEALTH STATUS BEFORE TREATMENT: } \\
\text { MEDICARE BENEFICIARIES WTH AMI AND MEDICARE BENEFICIARIES RECEIVING CABG,1987-94 }\end{array}$} \\
\hline & \multicolumn{2}{|c|}{$\begin{array}{lc}\text { BENEFICIARIES RECEIVING CABG } \\
\end{array}$} \\
\hline & $\begin{array}{l}\text { ASSUMES REPORT CARDS EFFECTIVE } \\
1991 \text { IN N.Y. AND } 1993 \text { IN PA }\end{array}$ & $\begin{array}{l}\text { ASSUMES REPORT CARDS EFFECTIV E } \\
1993 \text { IN N.Y AND PA. }\end{array}$ \\
\hline DEPENDENT V ARIABLE & (1) & (2) \\
\hline $\ln$ (CV of patierts total hospital expenditures one & $3.00 * *$ & $3.60 * *$ \\
\hline year prior to admision) & (1.39) & $(1.77)$ \\
\hline $\ln$ (CV of patients total days in hospital & 94 & 2.74 \\
\hline one year prion to admission) & $(2.22)$ & (3.53) \\
\hline
\end{tabular}

** Significantly different from 0 at the 5 percent level

Reproduced from Dranove et al. (2003) Table 2

Table 3-3

\section{Conclusion}

Providing a theoretical foundation to the empirical framework helps to shed new light on the studies of health care report cards. When professional and academic critics argue that the health care providers may use private patient information to "game" the system, a gametheoretical model is the best candidate to help us understand why they game and how. Based on a two-stage signaling game, I show that, when patients and providers are matched randomly, the trade-off between the measures in the existing report cards render them the optimal mechanism that reveal provider types without causing providers avoiding patients. Asymmetric distributions of patient types between providers caused by the referring physician, however, may force the high-quality provider to shun patients in order to separate himself from the lowquality one. The results imply that, in contrast to previous literature, a negative incidence effect alone can not be used to prove existence of selection behavior. Moreover, the traditional single difference-in-differences approach cannot be used to capture the long run welfare effect. More generally, I propose a new empirical framework where a difference-in-differences estimate is used for each treatment effect in each period. In addition my empirical framework calls for more attention to selection of the control group.

My results also clarify conventional wisdom on several accounts. First, many previous studies have mistaken the existing report cards as simply "mortality report cards", neglecting the fact that they actually show multidimensional measures. Such negligence results in not only flawed understanding of the existing report cards but also searching for new mechanisms in wrong directions. Second, at the patient level I argue that a healthier patient is foremost 
a patient, and no matter how healthy he will seek the best possible treatment. Thus it is incorrect to assume that healthier patients will choose the low-quality provider without conditions. Third, at the provider level I argue that a high-quality provider is not necessarily associated with a better outcome, because a sufficiently large patient volume will lower his performance.

Though the theoretical model I employ is a standard two-stage signaling game, it has the potential to be further extended to incorporate more realistic features, including word-ofmouth among patients, learning-by-doing of providers, and overlapping generations that allow providers to enter and exit.

The existence of selection behavior documented in previous literature may daunt people planing to introduce the report-card program to other fields in the health care industry and more broadly to other industries, such as law and education, where goods and services are also provided by skilled experts. My results help to clarify certain issues of concern. First, in the health care industry, we should recognize that though from an economics perspective whether a program should be implemented hinges on weighing between its benefit and cost, from a broader perspective, the decision may depend on whether we want to bear any cost in terms of denial or delay of treatments to some first period patients at all. Second, I show that providers' selection behavior is not caused by the report cards alone, rather it is caused by the combination of the report cards and the particular features of the health care industry. This implies the report-card program has the potential to be successfully introduced to other industries where good or service providers and consumers are randomly matched. Nevertheless, each industry is distinct in its own features, so the specific conclusions should be drawn upon a sufficient understanding of the industry where the report-card program is applied to. 


\section{Appendix 1}

\section{Proof of Lemma 1:}

Proof. Suppose the providers' types $\left(k_{i}, k_{-i}\right)$ are revealed at $t=2$, then the facts $F_{i t}()=$. $F($.$) and that each provider performs surgeries on all coming patients in period 2$ imply $E_{i 2}=1-\int_{-\infty}^{+\infty} q\left(s, M_{i 2}, k_{i}\right) d F(s)$ and $E_{-i 2}=1-\int_{-\infty}^{+\infty} q\left(s, 1-M_{i 2}, k_{-i}\right) d F(s)$. Following the discussion prior to the lemma, it must be $E_{i 2}=E_{-i 2}$ in equilibrium, which implies

$$
L\left(M_{i 2}\right) \equiv \int_{-\infty}^{+\infty} q\left(s, M_{i 2}, k_{i}\right)-q\left(s, 1-M_{i 2}, k_{-i}\right) d F(s)=0
$$

Since $L(1)=\int_{-\infty}^{+\infty}\left[1-q\left(s, 0, k_{-i}\right)\right] d F(s)>0, L(0)=\int_{-\infty}^{+\infty}\left[q\left(s, 0, k_{i}\right)-1\right] d F(s)<0$, and $L^{\prime}\left(M_{i 2}\right)=\int_{-\infty}^{+\infty} \frac{\partial}{\partial M_{i 2}} q\left(s, M_{i 2}, k_{i}\right)+\frac{\partial}{\partial\left(1-M_{i 2}\right)} q\left(s, 1-M_{i 2}, k_{-i}\right) d F(s)>0$, by the Intermediate Value Theorem, for every $\left(k_{i}, k_{-i}\right)$ there exists a unique $\hat{M}_{i 2}\left(k_{i}, k_{-i}\right)$ such that $E_{j i 2}=E_{j,-i 2}$.

By the Implicit Function Theorem, there is

$$
\begin{aligned}
& \int_{-\infty}^{+\infty}\left[\frac{\partial}{\partial k_{i}} q\left(s, \hat{M}_{i 2}, k_{i}\right)+\frac{\partial}{\partial \hat{M}_{i 2}} q\left(s, \hat{M}_{i 2}, k_{i}\right) \frac{\partial \hat{M}_{i 2}}{\partial k_{i}}+\frac{\partial}{\partial\left(1-\hat{M}_{i 2}\right)} q\left(s, 1-\hat{M}_{i 2}, k_{-i}\right) \frac{\partial \hat{M}_{i 2}}{\partial k_{i}}\right] d F(s) \\
= & \int_{-\infty}^{+\infty} \frac{\partial}{\partial k_{i}} q\left(s, \hat{M}_{i 2}, k_{i}\right) d F(s) \\
& +\frac{\partial \hat{M}_{i 2}}{\partial k_{i}} \cdot \int_{-\infty}^{+\infty}\left[\frac{\partial}{\partial M_{i 2}} q\left(s, \hat{M}_{i 2}, k_{i}\right)+\frac{\partial}{\partial\left(1-\hat{M}_{i 2}\right)} q\left(s, 1-\hat{M}_{i 2}, k_{-i}\right)\right] d F(s) \\
= & 0
\end{aligned}
$$

which implies $\frac{\partial \hat{M}_{i 2}}{\partial k_{i}}>0$ since $\frac{\partial}{\partial k_{i}} q\left(s, \hat{M}_{i 2}, k_{i}\right)<0$ and $\frac{\partial}{\partial M_{i 2}} q\left(s, \hat{M}_{i 2}, k_{i}\right)>0$.

Similarly, there is

$$
\begin{aligned}
& \int_{-\infty}^{+\infty}\left[\begin{array}{c}
\frac{\partial}{\partial M_{i 2}} q\left(s, \hat{M}_{i 2}, k_{i}\right) \frac{\partial \hat{M}_{i 2}}{\partial k_{-i}}-\frac{\partial}{\partial k_{-i}} q\left(s, 1-\hat{M}_{i 2}, k_{-i}\right) \\
+\frac{\partial}{\partial\left(1-\hat{M}_{i 2}\right)} q\left(s, 1-\hat{M}_{i 2}, k_{-i}\right) \frac{\partial \hat{M}_{i 2}}{\partial k_{-i}}
\end{array}\right] d F(s) \\
= & \frac{\partial \hat{M}_{i 2}}{\partial k_{-i}} \int_{-\infty}^{+\infty}\left[\frac{\partial}{\partial \hat{M}_{i 2}} q\left(s, \hat{M}_{i 2}, k_{i}\right)+\frac{\partial}{\partial\left(1-\hat{M}_{i 2}\right)} q\left(s, 1-\hat{M}_{i 2}, k_{-i}\right)\right] d F(s) \\
& -\int_{-\infty}^{+\infty} \frac{\partial}{\partial k_{-i}} q\left(s, 1-\hat{M}_{i 2}, k_{-i}\right) d F(s) \\
= & 0
\end{aligned}
$$

which implies $\frac{\partial \hat{M}_{i 2}}{\partial k_{-i}}<0$.

\section{Proof of Lemma 2}


Proof. Given $M_{i 1}$, for every $m_{i 1} \leq M_{i 1}$ there exists a unique severity level $s_{i}$ such that $m_{i 1}=M_{i 1} \cdot F\left(s_{i}\right)$. For each $m_{i 1} \leq M_{i 1}$, the minimum mortality rate $\bar{d}_{i 1}$ a provider $i$ can achieve comes from avoiding treating patients with $s_{j}>s_{i}$, implying

$$
\bar{d}_{i 1}=\frac{\int_{-\infty}^{s_{i}} q\left(s, m_{i 1}, k_{i}\right) d F(s)}{F\left(s_{i}\right)}=\frac{\int_{-\infty}^{s_{i}} q\left(s, M_{i 1} F\left(s_{i}\right), k_{i}\right) d F(s)}{F\left(s_{i}\right)}
$$

There are

$$
\left.\frac{\partial m_{i 1}}{\partial s_{i}}=M_{i 1} \cdot f\left(s_{i}\right)\right)>0
$$

and

$$
\begin{aligned}
\frac{\partial \bar{d}_{i 1}}{\partial s_{i}}= & \frac{\left[\begin{array}{c}
q\left(s_{i}, M_{i 1} F\left(s_{i}\right), k_{i}\right) \cdot f\left(s_{i}\right) \\
+\int_{-\infty}^{s_{i}} q_{2}\left(s, M_{i 1} F\left(s_{i}\right), k_{i}\right) \cdot M_{i 1} f\left(s_{i}\right) d F(s)
\end{array}\right] F\left(s_{i}\right)}{\left[F\left(s_{i}\right)\right]^{2}} \\
& -\frac{\int_{-\infty}^{s_{i}} q\left(s, M_{i 1} F\left(s_{i}\right), k_{i}\right) d F(s) \cdot f\left(s_{i}\right)}{\left[F\left(s_{i}\right)\right]^{2}} \\
> & \frac{\int_{-\infty}^{s_{i}} q_{3}\left(s, M_{i 1} F\left(s_{i}\right), k_{i}\right) \cdot M_{i 1} f\left(s_{i}\right) d F(s)}{F\left(s_{i}\right)}>0
\end{aligned}
$$

where the first inequality in the $\frac{\partial \bar{d}_{i 1}}{\partial s_{i}}$ part comes from $q\left(s, M_{i 1} \cdot F_{i 1}\left(s_{i}\right), k_{i}\right)<q\left(s_{i}, M_{i 1} \cdot F_{i 1}\left(s_{i}\right), k_{i}\right)$ for all $s<s_{i}$, as implied by Assumption 1-(i).

Since we can write $s_{i}$ as $s_{i}=F^{-1}\left(\frac{m_{i 1}}{M_{i 1}}\right)$, for $m_{i 1} \in\left(0, M_{i 1}\right]$ we can write $\bar{d}_{i 1}$ as

$$
\bar{d}_{i 1}\left(m_{i 1}\right)=\left[\int_{-\infty}^{F^{-1}\left(\frac{m_{i 1}}{M_{i 1}}\right)} q\left(s, m_{i 1}, k_{i}\right) d F(s)\right] \cdot \frac{m_{i 1}}{M_{i 1}}
$$

Consequently $\frac{\partial \bar{d}_{i 1}}{\partial m_{i 1}}=\frac{\partial \bar{d}_{i 1}}{\partial s_{i}} \cdot \frac{\partial s_{i}}{\partial m_{i 1}}>0$.

\section{Proof of Lemma 4:}

Proof. In the previous subsection we already know that in period 1 when all the other patients randomize between the providers with equal probabilities a patient will also be indifferent between choosing each provider on his own. Also we show that if all patients in period 1 equally randomize between the providers, then the type $k_{h}$ provider will perform surgeries on all the coming patients and thus reveals his type in period 2. Consequently the type $k_{l}$ provider will also perform surgeries on all the coming patients. To complete the proof, we only need to show that when all the other patients equally randomize between the providers, 
a patient will prefer this equal randomization to letting $C$ make the referral decision, that is,

$$
\begin{aligned}
& \frac{1}{2}\left[\int_{-\infty}^{+\infty} q\left(s, \frac{1}{2}, k_{l}\right) d F(s)+\int_{-\infty}^{+\infty} q\left(s, \frac{1}{2}, k_{h}\right) d F(s)\right] \\
< & \int_{-\infty}^{s_{1 / 2}} q\left(s, \frac{1}{2}, k_{l}\right) d F(s)+\int_{s_{1 / 2}}^{+\infty} q\left(s, \frac{1}{2}, k_{h}\right) d F(s)
\end{aligned}
$$

which implies

$$
\begin{aligned}
& \int_{-\infty}^{+\infty} q\left(s, \frac{1}{2}, k_{l}\right) d F(s)+\int_{-\infty}^{+\infty} q\left(s, \frac{1}{2}, k_{h}\right) d F(s) \\
< & 2\left[\int_{-\infty}^{s_{1 / 2}} q\left(s, \frac{1}{2}, k_{l}\right) d F(s)+\int_{s_{1 / 2}}^{+\infty} q\left(s, \frac{1}{2}, k_{h}\right) d F(s)\right]
\end{aligned}
$$

which implies

$$
\begin{aligned}
& \int_{s_{1 / 2}}^{+\infty} q\left(s, \frac{1}{2}, k_{l}\right) d F(s)+\int_{-\infty}^{s_{1 / 2}} q\left(s, \frac{1}{2}, k_{h}\right) d F(s) \\
< & \int_{-\infty}^{s_{1 / 2}} q\left(s, \frac{1}{2}, k_{l}\right) d F(s)+\int_{s_{1 / 2}}^{+\infty} q\left(s, \frac{1}{2}, k_{h}\right) d F(s)
\end{aligned}
$$

which after rearrangement leads to the inequality condition stated in the lemma.

\section{Proof of Lemma 5}

Proof. For the type $k_{h}$ provider, given $M_{h 1}$, for every $m_{h 1} \leq M_{h 1}$ there exists a unique $s_{h} \geq s_{1 / 2}$ such that

$$
m_{h 1}=M_{h 1} \cdot F_{h 1}\left(s_{h}\right)
$$

For each $m_{h 1} \leq M_{h 1}$, the minimum mortality rate $\bar{d}_{h 1}$ he can achieve comes from avoiding patients with $s_{j}>s_{h}$, implying

$$
\bar{d}_{h 1}=\frac{\int_{s_{1 / 2}}^{s_{h}} q\left(s, m_{h 1}, k_{h}\right) d F_{h 1}(s)}{F_{h 1}\left(s_{h}\right)}=\frac{\int_{s_{1 / 2}}^{s_{h}} q\left(s, M_{h 1} \cdot F_{h 1}\left(s_{h}\right), k_{h}\right) d F_{h 1}(s)}{F_{h 1}\left(s_{h}\right)}
$$

There are $\frac{\partial m_{h 1}}{\partial s_{h}}>0$ and $\frac{\partial \bar{d}_{h 1}}{\partial s_{h}}>0$. Moreover, for $s_{h} \geq s_{1 / 2}$ we can write $s_{h}$ as $s_{h}=F_{h 1}^{-1}\left(\frac{m_{h 1}}{M_{h 1}}\right)$, and so for $m_{h 1} \in\left(0, M_{h 1}\right]$ we can write $\bar{d}_{h 1}$ as

$$
\bar{d}_{h 1}\left(m_{h 1}\right)=\int_{s_{1 / 2}}^{F_{h 1}^{-1}\left(\frac{m_{h 1}}{M_{h 1}}\right)} q\left(s, m_{h 1}, k_{h}\right) d F_{h 1}(s) \cdot \frac{m_{h 1}}{M_{h 1}}
$$


It follows that $\frac{\partial \bar{d}_{h 1}}{\partial m_{h 1}}=\frac{\partial \bar{d}_{h 1}}{\partial s_{h}} \cdot \frac{\partial s_{h}}{\partial m_{h 1}}>0$ and $\frac{\partial \bar{d}_{h 1}}{\partial k_{h}}<0$.

Similarly, for the type $k_{l}$ provider, given $M_{l 1}$, for every $m_{l 1} \leq M_{l 1}$ there exists a unique $s_{l} \leq s_{1 / 2}$ such that

$$
m_{l 1}=M_{l 1} \cdot F_{l 1}\left(s_{l}\right)
$$

For each $m_{l 1} \leq M_{l 1}$, the minimum mortality rate $\bar{d}_{l 1}$ he can achieve comes from avoiding treating patients with $s_{j}>s_{l}$, implying

$$
\bar{d}_{l 1}=\frac{\int_{-\infty}^{s_{l}} q\left(s, m_{l 1}, k_{l}\right) d F_{l 1}(s)}{F_{l 1}\left(s_{l}\right)}=\frac{\int_{-\infty}^{s_{l}} q\left(s, M_{l 1} \cdot F_{l 1}\left(s_{l}\right), k_{l}\right) d F_{l 1}(s)}{F_{l 1}\left(s_{l}\right)}
$$

There are $\frac{\partial m_{l 1}}{\partial s_{l}}>0$ and $\frac{\partial \bar{d}_{l 1}}{\partial s_{l}}>0$. Moreover, for $s_{l}<s_{1 / 2}$ we can write $s_{l}$ as $s_{l}=F_{l 1}^{-1}\left(\frac{m_{l 1}}{M_{l 1}}\right)$, and so for $m_{l 1} \in\left(0, M_{l 1}\right]$ we can write $\bar{d}_{l 1}$ as

$$
\bar{d}_{l 1}\left(m_{l 1}\right)=\int_{-\infty}^{F_{l 1}^{-1}\left(\frac{m_{l 1}}{M_{l 1}}\right)} q\left(s, m_{l 1}, k_{l}\right) d F_{l 1}(s) \cdot \frac{m_{l 1}}{M_{l 1}}
$$

It follows that $\frac{\partial \bar{d}_{l 1}}{\partial m_{l 1}}=\frac{\partial \bar{d}_{l 1}}{\partial s_{l}} \cdot \frac{\partial s_{l}}{\partial m_{l 1}}>0$ and $\frac{\partial \bar{d}_{l 1}}{\partial k_{l}}<0$.

\section{Consistent belief system supporting the separating equilibrium in Proposition 2:}

Proof. To support the equilibrium strategies, the patients' off-equilibrium-path belief can be constructed accordingly. We focus on the two cases $k_{h} \in\left(k_{b}, \bar{k}_{h}\right)$ and $k_{h} \in\left(k_{l}, k_{b}\right]$, as the other two cases are straightforward. Note that we only need to be concerned with two categories of the patients' off-equilibrium-path belief, one with a provider $i$ 's report card being $\left(m_{i 1}, d_{i 1}\right)=\left(\frac{1}{2}, \bar{d}_{l 1}\left(\frac{1}{2}\right)\right)$ and the other with a provider $i$ 's report card being $\left(m_{i 1}, d_{i 1}\right)=$ $\left(m_{h 1}^{*}, \bar{d}_{h 1}\left(m_{h 1}^{*}\right)\right)$. First, for $k_{h} \in\left(k_{b}, \bar{k}_{h}\right)$, for the type $k_{h}$ provider not to deviate, the patients can hold the belief that if $\left(m_{i 1}, d_{i 1}\right)=\left(\frac{1}{2}, \bar{d}_{l 1}\left(\frac{1}{2}\right)\right)$ but $m_{-i 1}>\bar{m}\left(k_{h}, k_{l}\right)-\varepsilon$ then $k_{i}=k_{h}$ and $k_{-i}=k_{l}$. For the type $k_{l}$ provider not to deviate, the patients can hold the belief that if $\left(m_{i 1}, d_{i 1}\right)=\left(\bar{m}\left(k_{h}, k_{l}\right)-\varepsilon, \bar{d}_{h 1}\left(\bar{m}\left(k_{h}, k_{l}\right)-\varepsilon\right)\right)$ but $\left(m_{-i 1}, d_{-i 1}\right) \neq\left(\frac{1}{2}, \bar{d}_{l 1}\left(\frac{1}{2}\right)\right)$ then $k_{i}=k_{h}$ and $k_{-i}=k_{l}$. Second, for $k_{h} \in\left(k_{l}, k_{b}\right]$, for the type $k_{h}$ provider not to deviate, the patients can hold the belief that if $\left(m_{i 1}, d_{i 1}\right)=\left(\frac{1}{2}, \bar{d}_{l 1}\left(\frac{1}{2}\right)\right)$ but $\left(m_{-i 1}, d_{-i 1}\right) \neq\left(1-M_{h}^{*}\left(k_{h}, k_{l}\right), \bar{d}_{h 1}\left(1-M_{h}^{*}\left(k_{h}, k_{l}\right)\right)\right)$ then $k_{i}=k_{h}$ and $k_{-i}=k_{l}$. For the type $k_{l}$ provider not to deviate, the patients can hold the belief that (i) if $\left(m_{i 1}, d_{i 1}\right)=\left(1-M_{h}^{*}\left(k_{h}, k_{l}\right), \bar{d}_{h 1}\left(1-M_{h}^{*}\left(k_{h}, k_{l}\right)\right)\right)$ but $\left(m_{-i 1}, d_{-i 1}\right) \neq\left(m_{i 1}, d_{i 1}\right)$ and $\left(m_{-i 1}, d_{-i 1}\right) \neq\left(\frac{1}{2}, \bar{d}_{l 1}\left(\frac{1}{2}\right)\right)$, then $k_{i}=k_{h}, k_{-i}=k_{l}$, and (ii) if $\left(m_{i 1}, d_{i 1}\right)=\left(m_{-i 1}, d_{-i 1}\right)=$ $\left(1-M_{h}^{*}\left(k_{h}, k_{l}\right), \bar{d}_{h 1}\left(1-M_{h}^{*}\left(k_{h}, k_{l}\right)\right)\right)$, then $\operatorname{Pr}\left(k_{i}=k_{h}\right)=\frac{1}{2}$. 


\section{Appendix 2}

Sample of New York CABG report card, hospital level, 1994

Table 2: Hospital Observed, Expected and Risk-Adjusted Mortality Rates for Coronary Artery Bypass Grafts in New York State, 1994 Discharges (Listed Alphabetically by Hospital)

\begin{tabular}{lrrrrrr}
\hline Hospital & Cases & Deaths & \multicolumn{1}{l}{ OMR } & EMR & RAMR & $\begin{array}{c}\text { 95\% Cl } \\
\text { for RAMR }\end{array}$ \\
\hline Albany Medical Center & 1167 & 18 & 1.54 & 1.93 & 1.98 & $(1.18,3.14)$ \\
Arnot-Ogden & 236 & 4 & 1.69 & 2.42 & 1.74 & $(0.47,4.45)$ \\
Bellevue & 93 & 6 & 6.45 & 2.28 & $7.05^{*}$ & $(2.57,15.34)$ \\
Beth Israel & 270 & 4 & 1.48 & 2.98 & 1.24 & $(0.33,3.17)$ \\
Buffalo General & 1173 & 25 & 2.13 & 1.95 & 2.71 & $(1.75,4.00)$
\end{tabular}

Sample of Pennsylvania CABG report card, hospital level and surgeon level, 1994-95

Risk-Adjusted In-hospital Mortality Outcomes

FIGURE 3B: Actual to Expected Mortality, by Cardiac Surgeon, 1994-1995

CENTRAL AND NORTHEASTERN PENNSYLVANIA

Altoona Hospital

Anastasi, John S.

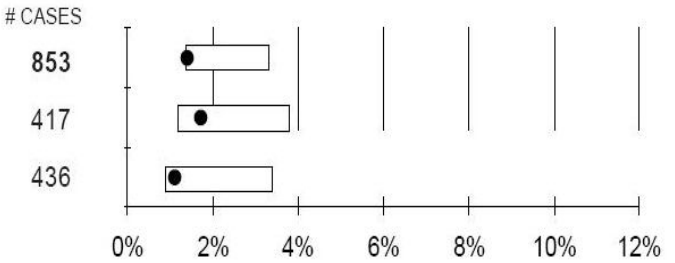

Conemaugh Valley Memorial Hospital

Devineni, Rajsekhar

Kolff, Jacob

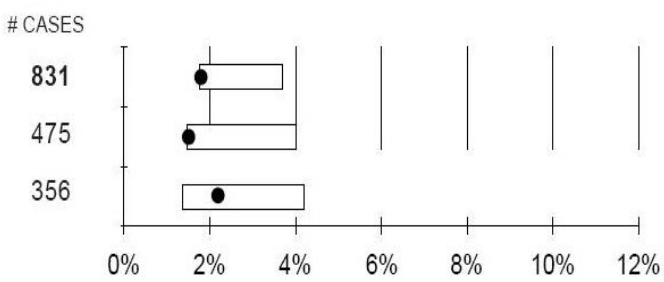




\section{References}

Burack, J. H., P. Impellizzeri, P. Homel, and J. N. Cunningham Jr. 1999. "Public reporting of surgical mortality: A survey of New York State cardiothoracic surgeons." Annals of Thoracic Surgery 68 (4): 1195-1202.

Cameron A. C., Trivedi, P. K., "Microeconometrics: Methods and Applications", ISBN 0521848059, page 768-769

Capps, C., Dranove D., Greenstein S. and Satterthwaite M., 2001. "The Silent Majority Fallacy of the Elzinga-Hogarty Criteria: A Critique and New Approach to Analyzing Hospital Mergers." NBER Working Paper 8216

Chassin, M. R.,Hannan, E. L., and DeBuono, B. A., 1996. "Benefits and hazards of reporting medical outcomes publicly". New England Journal of Medicine 334 (6):394-98.

Chen, Y., 2008, "Character Evidence and Regulation of Skilled Experts", Working Paper, University of Pennsylvania

Dranove, D., Kessler, D., McClellan M., Satterthwaite. M., 2003. "Is More Information Better? The Effects of 'Report Cards' on Health Care Providers." Journal of Political Economy 111(3):555-588.

Epstein, A. J., 2004. "Understanding incentives for responding to report cards". Ph.D. diss., University of Pennsylvania.

Epstein, A. J., 2006. "Do Cardiac Surgery Report Cards Reduce Mortality? Assessing the Evidence", Medical Care Research and Review 63(4):403-426.

Fong, K., 2007, "Evaluating Skilled Experts: Optimal Scoring Rules for Surgeons", Ph.D. Dissertation Paper, Stanford University

Fudenberg, D., Tirole, J., "Game Theory", 1991, ISBN 0262061414, page 34, 319-364

Gibbs, D.A., Sangl J. A., and Burrus B. 1996. "Consumer perspectives on information needs for health plan choice". Health Care Financ Rev, 18(1):55-74.

Hannan, E. L., C. Stone, T. L. Biddle, and B. A. DeBuono. 1997. "Public release of cardiac surgery outcomes data in New York: What do New York State cardiologists think of it?" American Heart Journal 134 (6): 1120-28. 
Harlan, B. J. 2001. "Statewide reporting of coronary artery surgery results: A view from California". Journal of Thoracic and Cardiovascular Surgery 121 (3): 409-17.

Hartz, A. J., E. M. Kuhn, and H. Krakauer. 1996. "The relationship of the value of outcome comparisons to the number of patients per provider". International Journal for Quality in Health Care 9 (4): 247-54.

Kulick D. L. (M.D.), 2005, "The New 'Coated' Stents - What's The Story?", www.medicinenet.com

Localio, A. R., B. H. Hamory, A. C. Fisher, and T. R. TenHave. 1997. The public release of hospital and physician mortality data in Pennsylvania: A case study. Medical Care 35 (3): $272-86$.

Lu M., Ma C. A., Yuan L., 2003, "Risk selection and matching in performance-based contracting", Health Economics, 12: p339-354.

Mukamel, D. B., and A. I. Mushlin. 1998. "Quality of care information makes a difference: An analysis of market share and price changes after publication of the New York State cardiac surgery mortality reports". Medical Care 36 (7): 945-54.

Mukamel D.B., D.L. Weimer, J. Zwanziger, and A. I. Mushlin. 2002. "Quality of cardiac surgeons and managed care contracting practices". Health Services Research 37 (5): 1129-44.

Mukamel, D. B., D. L. Weimer, J. Zwanziger, S. F. H. Gorthy, and A. I. Mushlin. 2004. "Quality report cards, selection of cardiac surgeons and racial disparities: A study of the publication of the New York State cardiac surgery reports." Inquiry 41 (4): 435-46.

New York State Department of Health, "Cardiovascular Disease Data and Statistics, Adult Cardiac Surgery in New York State, 1992-1994", November 1998, http://www.health.state.ny.us

Omoigui, Nowamagbe A., Dave P. Miller, Kimberly J. Brown, Kingsley Annan, Delos Cosgrove, Bruce Lytle, Floyd Loop \& Eric J. Topol. 1996. "Outmigration for Coronary Bypass Surgery in An Era of Public Dissemination of Clinical Outcomes." Circulation 93:2733.

Phelps, C., "Health Economics", 3rd Edition, ISBN 0-321-06898-X, page 370, 375

Pauly, M.V., and Satterthwaite, M.A., "The Pricing of Primary Care Physician' Services: A Test of the Role of Consumer Information," Bell Journal of Economics 1981; 12:488-506 
Pennsylvania Health Care Cost Containment Council, "Pennsylvania's Guide to Coronary Artery Bypass Graft Surgery 1994-1995", May 1998, http://www.phc4.org/reports/cabg/95/default.htm

Peterson, E. D., E. R. DeLong, J. G. Jollis, L. H. Muhlbaier, and D. B. Mark. 1998. "The effects of New York's bypass surgery provider profiling on access to care and patient outcomes in the elderly". Journal of the American College of Cardiology 32 (4): 993-99.

Ramanarayanan, S., 2006, "Does Practice Make Perfect? An Empirical Analysis of Learningby-Doing in Cardiac Surgery", Job Market Paper, Northwestern University

Raffel M. W. \& Barsukiewicz C. K., "The U.S. Health System, Origins and Functions", 5th Edition, ISBN 0-7668-0714-2, page 32-33, 126

Rupprecht, H., Brennecke, R., Bernhard, G., Erbel, R., Pop, T., Meyer, J., 2005, "Analysis of risk factors for restenosis after PTCA", Catheterization and Cardiovascular Diagnosis, Volume 19 Issue 3, Pages 151 - 159

Satterthwaite, M.A., 1979, "Consumer Information, Equilibrium, Industry Price, and the Number of Sellers", Bell Journal of Economics, 10(2): 483-502

Schneider, E. C., and A. M. Epstein. 1996 "Influence of cardiac-surgery performance reports on referral practices and access to care: A survey of cardiovascular specialists". New England Journal of Medicine 335 (4): 251-56.

- 1998. Use of public performance reports: A survey of patients undergoing cardiac surgery. Journal of the American Medical Association 279 (20): 1638-42.

Spence M., 1973, "Job Market Signaling", The Quarterly Journal of Economics, Vol. 87, No. 3., pp. 355-374. 